\title{
A study of the effect of overshooting deep convection on the water content of the TTL and lower stratosphere from Cloud Resolving Model simulations
}

\author{
D. P. Grosvenor ${ }^{1}$, T. W. Choularton ${ }^{1}$, H. Coe ${ }^{1}$, and G. Held ${ }^{2}$ \\ ${ }^{1}$ The University of Manchester, Manchester, UK \\ ${ }^{2}$ Instituto de Pesquisas Meteorológicas, Universidade Estadual Paulista, 17015-970 BAURU, S.P., Brasil
}

Received: 4 May 2007 - Published in Atmos. Chem. Phys. Discuss.: 30 May 2007

Revised: 12 September 2007 - Accepted: 17 September 2007 - Published: 28 September 2007

\begin{abstract}
Simulations of overshooting, tropical deep convection using a Cloud Resolving Model with bulk microphysics are presented in order to examine the effect on the water content of the TTL (Tropical Tropopause Layer) and lower stratosphere. This case study is a subproject of the HIBISCUS (Impact of tropical convection on the upper troposphere and lower stratosphere at global scale) campaign, which took place in Bauru, Brazil $\left(22^{\circ} \mathrm{S}, 49^{\circ} \mathrm{W}\right)$, from the end of January to early March 2004.

Comparisons between 2-D and 3-D simulations suggest that the use of 3-D dynamics is vital in order to capture the mixing between the overshoot and the stratospheric air, which caused evaporation of ice and resulted in an overall moistening of the lower stratosphere. In contrast, a dehydrating effect was predicted by the 2-D simulation due to the extra time, allowed by the lack of mixing, for the ice transported to the region to precipitate out of the overshoot air.

Three different strengths of convection are simulated in 3-D by applying successively lower heating rates (used to initiate the convection) in the boundary layer. Moistening is produced in all cases, indicating that convective vigour is not a factor in whether moistening or dehydration is produced by clouds that penetrate the tropopause, since the weakest case only just did so. An estimate of the moistening effect of these clouds on an air parcel traversing a convective region is made based on the domain mean simulated moistening and the frequency of convective events observed by the IPMet (Instituto de Pesquisas Meteorológicas, Universidade Estadual Paulista) radar (S-band type at $2.8 \mathrm{Ghz}$ ) to have the same $10 \mathrm{dBZ}$ echo top height as those simulated. These suggest a fairly significant mean moistening of $0.26,0.13$ and 0.05 ppmv in the strongest, medium and weakest cases, respectively, for heights between 16 and $17 \mathrm{~km}$. Since the cold point and WMO (World Meteorological Organization)
\end{abstract}

Correspondence to: D. P. Grosvenor

(daniel.grosvenor@manchester.ac.uk) tropopause in this region lies at $\sim 15.9 \mathrm{~km}$, this is likely to represent direct stratospheric moistening. Much more moistening is predicted for the $15-16 \mathrm{~km}$ height range with increases of $0.85-2.8$ ppmv predicted. However, it would be required that this air is lofted through the tropopause via the Brewer Dobson circulation in order for it to have a stratospheric effect. Whether this is likely is uncertain and, in addition, the dehydration of air as it passes through the cold trap and the number of times that trajectories sample convective regions needs to be taken into account to gauge the overall stratospheric effect. Nevertheless, the results suggest a potentially significant role for convection in determining the stratospheric water content.

Sensitivity tests exploring the impact of increased aerosol numbers in the boundary layer suggest that a corresponding rise in cloud droplet numbers at cloud base would increase the number concentrations of the ice crystals transported to the TTL, which had the effect of reducing the fall speeds of the ice and causing a $\sim 13 \%$ rise in the mean vapour increase in both the 15-16 and 16-17 km height ranges, respectively, when compared to the control case. Increases in the total water were much larger, being $34 \%$ and $132 \%$ higher for the same height ranges, but it is unclear whether the extra ice will be able to evaporate before precipitating from the region. These results suggest a possible impact of natural and anthropogenic aerosols on how convective clouds affect stratospheric moisture levels.

\section{Introduction}

The amount of water vapour in the stratosphere can significantly affect the Earth's climate since it is the most important greenhouse gas in the atmosphere. Additionally, it is one of the main sources of ozone destroying $\mathrm{OH}$ hydroxyl radicals and is involved in the formation of Polar Stratospheric Clouds, which also help to destroy ozone.

Published by Copernicus Publications on behalf of the European Geosciences Union. 
Understanding what affects the stratospheric water vapour content is therefore vitally important, even more so in light of observations that suggest that it has been increasing by $\sim 1 \%$ per year over the past 50 years (Oltmans and Hofmann, 1995; Rosenlof et al., 2001). About half of this is attributed to changes in the processes affecting the entry of water vapour into the stratosphere from the troposphere, with the rest due to increases in methane amounts. Determining what affects the vapour content during troposphere to stratosphere transport then becomes key to understanding this increase and hence how it might alter in a changing climate.

To date the tropical slow uplift and "freeze-drying" mechanism of Brewer (1949) is still accepted as broadly controlling the amount of water vapour entering the stratosphere. Here vapour is assumed to be reduced towards the relatively low ice saturation mixing ratios at the cold temperatures of the tropical tropopause by ice formation and subsequent vapour deposition, with the ice falling out of the rising air.

Trajectory studies based on ECMWF model wind and temperature fields (Fueglistaler et al., 2004) suggested that $70 \%$ of the air parcels traversing from the troposphere to the stratosphere reached their minimum temperature over the western Pacific, where the coldest tropopause temperatures are found, but found no evidence for the majority also crossing the tropopause in that region and hence little evidence for the "stratospheric fountain" region (as proposed by Newell and Gould-Stewart, 1981). This is feasible because the slow uplift rate of the Brewer Dobson circulation (mean global scale velocity of $\sim 0.5 \mathrm{~mm} \mathrm{~s}^{-1}$ ) combined with relatively large horizontal winds of the order of $5 \mathrm{~m} \mathrm{~s}^{-1}$ allows air parcels to travel horizontal distances of several thousand kilometres whilst ascending vertically by only a few hundred metres (Holton and Gettelman, 2001).

Furthermore, the water vapour mixing ratios of trajectories on entry into the stratosphere, as reported in Fueglistaler et al. (2004), Fueglistaler and Haynes (2005) and Fueglistaler et al. (2005), were found to be broadly consistent with satellite observations of the lower stratospheric vapour content. This suggests that processes that potentially affect stratospheric vapour content, but which are not included in the ECMWF model, such as the effects of deep convection or the microphysical details of ice formation and sedimentation, may be of secondary importance compared to the environmental temperature experienced by air during troposphere to stratosphere transport.

A potential problem comes from the fact that the correlation between mean tropopause temperatures and stratospheric vapour mixing ratios found in Fueglistaler and Haynes (2005) is at odds with the observed long-term increase in stratospheric water vapour in light of mean tropical tropopause temperatures from radiosonde observations that have been reported as decreasing by $\sim 0.57 \mathrm{~K} \mathrm{decade}^{-1}$ between 1973-1998 (Zhou et al., 2001) or by $\sim 0.5 \mathrm{~K} \mathrm{decade}^{-1}$ between 1978-1997 (Seidel et al., 2001). Using trajectories based in the 1960s, Fueglistaler and Haynes (2005) found no differences when compared to trajectories based in times closer to the present that could account for the long-term trend in water vapour, indicating that factors other than dynamical pathways and the environmental temperature may be of importance after all, unless the observed increases in stratospheric water vapour are incorrect.

The effects of deep convection on the stratospheric water vapour entry mixing ratio is one such pathway that may offer an explanation of the long-term trend in water vapour. Dehydration of air entering the stratosphere by overshooting deep convective clouds has been previously suggested by several authors, e.g. Danielsen (1982), Holton et al. (1995) and Sherwood and Dessler (2001). If convection overshoots its level of neutral buoyancy it becomes colder than the environment, thus possibly allowing dehydration down to lower vapour mixing ratios than would occur during slow ascent in equilibrium with the environment temperature. However, such clouds are likely to carry large amounts of ice into the TTL region and therefore, if sufficient ice is not removed by sedimentation, then there is also the possibility of moistening of the air bound for the stratosphere.

Deep convective effects on the TTL water content are likely to be much more complex than freeze drying linked to low temperatures alone. Various dynamical and microphysical processes occurring in the clouds are involved, which could be affected by environmental changes throughout the troposphere. Changes to these processes over long time scales could result in dehydration and/or moistening changes despite trends in tropopause temperatures. One example is an increase in aerosol loadings, which may have occurred due to the increasing urbanisation of previously unspoilt areas in the tropics (Gupta, 2002) or through increases in biomass burning (Sherwood, 2002), for example.

Aerosol increases may lead to smaller ice crystals being transported in the overshooting clouds, causing less dehydration or more moistening due to the smaller ice failing to fall from the detrained air. Indeed, Sherwood (2002) found correlations between the stratospheric moisture content and the effective diameter of ice crystals in the upper troposphere as measured by satellite instruments. The variations observed were approximately semi-annular and hence not correlated with the tropopause temperature seasonal cycle, but rather seemed to coincide with periods of biomass burning. Increases in the latter have been observed over the same period as the stratospheric water vapour increase, suggesting an explanation for the lack of correlation with tropopause temperatures.

In this work a Cloud Resolving Model (CRM) will be used to examine how single overshooting deep convective clouds might affect the water content of the TTL. There have been relatively few such studies in the past. Küpper et al. (2004) used the same CRM as in this work and looked at the convective effect over a timescale of 100 days by running the model to convective equilibrium. The results showed no convective dehydration and that the non-convective flux of water 
through the cold point was several times greater than the convective flux, although the latter dominated at heights below there and hence possibly into the lower TTL. However, it is likely that the most vigorous of convection that occurs in reality over the continents of the tropics or in organised systems was not represented. The modelling work presented in this paper makes no attempt to simulate the frequency of convective events but does examine the effect of more vigorous overshooting events. Wang (2003) used a CRM to look at overshooting mid-latitude convection and found that plumes of water vapour were produced in the stratosphere due to gravity wave breaking at the cloud top. Chaboureau et al. (2007) simulated an overshooting, deep convective event using a mesoscale model initialised using real meteorological conditions and based in the same area as the simulations presented here, which suggested that such events might cause a significant flux of water vapour into the stratosphere. The current work differs in that single idealised cells are simulated, which allows sensitivities to convective vigour and microphysics to be investigated. In addition, the model used here allows for ice supersaturation, in contrast to the microphysics scheme employed in Chaboureau et al. (2007).

Assessing the effect of deep convection on the stratosphere is more pertinent given recent data that suggests that convective penetration into the TTL occurs significantly more frequently than previously thought (Dessler et al., 2006) and that the amount of ice injected may be hydrologically important (Wu et al., 2005). CRMs probably represent the most useful modelling tool available for examination of the complex dynamical and microphysical details of how deep convection affects the water content of the TTL and the sensitivities involved. Before they can be employed with confidence, though, their suitability needs to be investigated through comparisons to observations and exploration of the sensitivities to the set up of the models.

\section{Model set up and the case study day}

\subsection{The LEM Cloud Resolving Model}

The CRM being used in these studies is the UK Met Office LEM (Large Eddy Model) v2.3, as described in Shutts and Gray (1994), albeit with some modifications. It explicitly solves for large-scale motions using a quasi-Boussinesq non-hydrostatic equation set and parameterizes small-scale sub-grid turbulent motions based on the Smagorinsky-Lilly approach. Details of this parameterization can be found in Brown et al. (1994). Surface boundary conditions are derived from the Monin-Obukhov similarity theory using the Businger-Dyer functions. The upper boundary condition is of the form of a rigid lid, but with a damping layer in the upper domain to prevent reflection of gravity waves.

The LEM uses a bulk microphysics scheme, which parameterises conversions between water vapour, liquid water

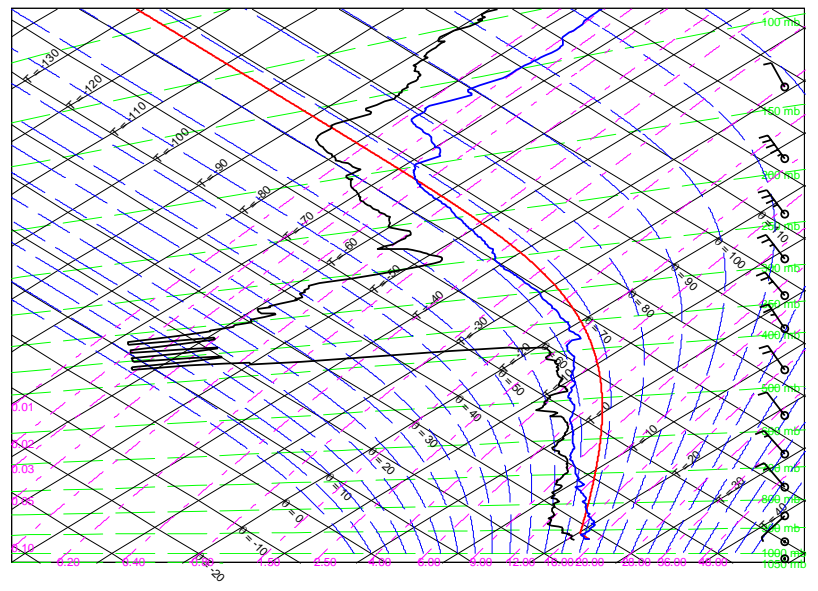

Fig. 1. Sounding from Bauru, 24 February 2004 at 20:15 UTC.

droplets, rain, ice (small ice crystals), snow (low density ice aggregates) and graupel (heavily rimed ice particles), as well as their fall speeds. In order to do this, it assumes that the size spectrum of each hydrometeor is a gamma-type function with coefficients adjustable for each type. The model is single moment for vapour, liquid and rain; i.e., it only has variables for their mass mixing ratios. It is double moment for ice, snow and graupel, in that it can predict both their mixing ratios and number concentrations. The ice scheme is based on Lin et al. (1983), Rutledge and Hobbs (1984), Ferrier (1994) and Ferrier et al. (1995), with refinements from Flatau (1989), Swann (1996) and Swann (1998). The model allows supersaturation of the vapour field with respect to ice with ice being heterogeneously nucleated as a function of this, as based on the Meyers et al. (1992) scheme. Vapour deposition onto ice is based on the supersaturation, the mass and number of the ice field and the assumed shape of the size distributions.

\subsection{Meteorology and model initialisation}

The simulations shown here were based on a case study day of the 2004 HIBISCUS project, which took place in Bauru, Brazil, located at $22.3^{\circ} \mathrm{S}, 49.03^{\circ} \mathrm{W}$. The day chosen was 24 February, when a sounding (Fig. 1) was made at 20:15 UTC, which is 17:15 LT (local time). It shows a pronounced dry layer centred at $\sim 8.5 \mathrm{~km}$ with the cold point and WMO tropopause occurring at $\sim 15.9 \mathrm{~km}(112 \mathrm{mb}-$ see the end of this section for a discussion on the TTL location). The CAPE (Convective Available Potential Energy) of the sounding was a moderate $1095 \mathrm{~J} \mathrm{~kg}^{-1}$ and the presence of an inversion above the boundary layer resulted in CIN (Convective Inhibition) of $\sim 111 \mathrm{~J} \mathrm{~kg}^{-1}$.

Other radiosonde ascents performed on this day from Campo Grande $(610 \mathrm{~km}$ west-north-west of Bauru, at 00:00 


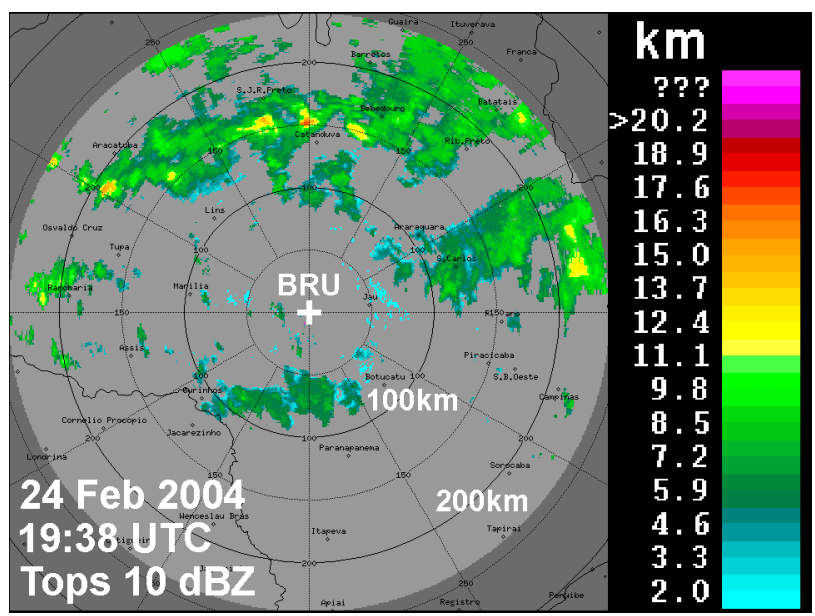

Fig. 2. Echo tops (reflectivity threshold $10 \mathrm{dBZ}$ ) observed by the S-band radar in Bauru at 19:38 UTC (=local time+3).

and 12:00 UTC as well as vertical profiles derived at 3-hourly intervals from the Meso-Eta operational mesoscale model (Black, 1994) as run by CPTEC (Centre for Weather Forecast and Climatic Studies) for the South American continent, showed CAPE values of between 1144 and $2389 \mathrm{~J} \mathrm{~kg}^{-1}$ throughout the day, signalling the potential for the development of severe storms. Cloud tops observed by IPMet's radars (S-band type at $2.8 \mathrm{Ghz}$ ) were mostly $<14 \mathrm{~km}$, but a few cells penetrated through the tropopause (tops $>18 \mathrm{~km}$ at times) during the late afternoon (Fig. 2). Cloud top estimations from the radar are based on the $10 \mathrm{dBZ}$ echo top for which the errors should be within $1 \mathrm{~km}$ for $20 \mathrm{~km}$ high clouds at the edge of the radar range and considerably less for clouds that are lower or closer to the radar. Further description of the storms that occurred on this day can be found in Pommereau et al. (2007).

At the time of the radiosonde launch (20:15 UTC), the convective area was $\geq 100 \mathrm{~km}$ north-west to north-east of the radar, with echo tops mostly $<10 \mathrm{~km}$, but isolated cells reached up to $15 \mathrm{~km}$. The rain area south of Bauru was already in the dissipation stage. The convection continued throughout the night. Since the closest radiosonde available, viz. Bauru at 20:15 UTC, was released after the initiation of convective events, it is likely that there may be some discrepancies between these measurements and the environment that the storms actually formed in, especially in the lower layers, which are subject to heating and moistening, as well as lowlevel convergence processes.

The latter is known to be occurring in the region as a result of the semi-stationary South Atlantic Convergence Zone (SACZ). This can be identified from satellite images as a cloud band with orientation NW/SE, which commonly extends from the southern region of Amazônia into the central region of the South Atlantic (Kousky, 1988), with a typical persistence of $\geq 4$ days. It forms along the upper-level

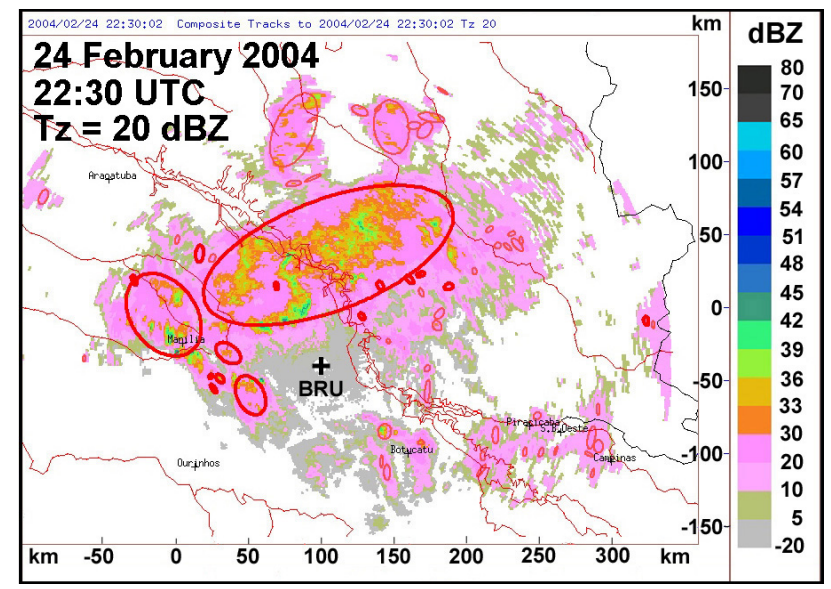

Fig. 3. TITAN-generated image (MDV format) of the storm complex on 24 February 2004 at 22:30 UTC. The ellipses demarcate centroids of $20 \mathrm{dBZ}$ reflectivity threshold with a minimum volume of $16 \mathrm{~km}^{3}$

subtropical jet and to the east of a semi-stationary trough over south-eastern South America, approximately along the Brazilian and Uruguayan coasts at $500 \mathrm{hPa}$. It is characterized by low-level humidity convergence zones, a strong gradient of the equivalent potential temperature in the middle troposphere and an anticyclonic circulation at high levels $(200 \mathrm{hPa})$. Being located at the edge of humid tropical air masses, in regions of strong humidity gradients at low levels, it results in the generation of strong and extensive convective instability. The occurrences of SACZ play an important role in the transfer of latent heat, momentum and humidity from the tropics to the mid-latitudes and are responsible for the most humid periods and heavy summer rainfalls in the State of São Paulo.

Detailed analysis of radar-derived parameters, using IPMet's newly implemented software package TITAN (Thunderstorm Identification, Tracking, Analysis and Nowcasting; Dixon and Wiener, 1993) with a $20 \mathrm{dBZ}$ reflectivity threshold and a volume of $\geq 16 \mathrm{~km}^{3}$ for the identification of the centroid, confirmed the existence of a large multicellular storm complex, lasting for $14.6 \mathrm{~h}$, with a maximum precipitation area of $14049 \mathrm{~km}^{2}$. Figure 3 depicts this complex in TITAN MDV format (Meteorological Data Volume; Dixon and Wiener, 1993), shortly before reaching Bauru. The large ellipsis demarcates the envelope of the $20 \mathrm{dBZ}$ centroid, which was tracked to calculate the storm parameters. The Vertically Integrated Liquid water content (VIL), another indicator of severity, exceeded $7 \mathrm{~kg} \mathrm{~m}^{-2}$ (currently used at IPMet to trigger alerts; (Gomes and Held, 2004) on 11 occasions between 18:57 and 24:07 UTC, with a maximum of $8.3 \mathrm{~kg} \mathrm{~m}^{-2}$ at 23:37 UTC.

As the Bauru sounding showed some CIN and represented the lower end of the range of CAPE suggested by soundings and mesoscale models, and since the aim here was to 
simulate some extreme cases of convection, it was decided to initiate convection by producing a warm and moist bubble in order to artificially increase the CAPE of the environment and to help represent the influx of moist, tropical air as caused by the SACZ. Warm bubbles have been used to initiate deep convection in several CRM studies in the past. In Wang (2003) a $20 \mathrm{~km} \times 4 \mathrm{~km}$ warm bubble of maximum perturbation $3.5 \mathrm{~K}$ was imposed, which was made moister than its surroundings since the relative humidity was kept constant as its temperature increased. In this study the bubble was applied gradually using a heating and moistening rate in the lower $2.5 \mathrm{~km}$ of the model domain over a width of $14 \mathrm{~km}$, with the rate decreasing according to a $\cos ^{2}$ relationship with radial distance from the centre. They were applied for twenty minutes, beginning $5 \mathrm{~min}$ after the simulation start and the simulations were performed up to a time of $3 \mathrm{~h} 35 \mathrm{~min}$. Runs with different heating rates, but with the same rate of moisture input, were performed in order to simulate convection with a variety of different strengths. These runs are labelled "3D-med" and "3D-weak" to indicate cells of medium and weaker intensity, with the original case labelled as " $3-\mathrm{D}$ ".

One 2-D case was simulated (labelled "2-D") in which the model domain was $2000 \mathrm{~km}$ wide with a $2 \mathrm{~km}$ horizontal resolution. Such a large domain was required because of interactions of gravity waves emanating from both sides of the cloud due to the periodic boundary conditions of the model, which interfered with the air from the overshoot. This is much less of an issue in 3-D since the gravity waves produced are somewhat smaller in velocity magnitude than in 2-D. Therefore, in this case the domain is $300 \times 300 \mathrm{~km}$ in the "3-D" case and, for computational reasons, only $150 \times 150 \mathrm{~km}$ in the "3D-med" and "3D-weak" sensitivity tests, with the same resolution. The vertical grid in all cases is $30.4 \mathrm{~km}$ deep with the damping layer applied over the upper $7.6 \mathrm{~km}$ of the domain. The vertical resolution was $75 \mathrm{~m}$ in the boundary layer and $125 \mathrm{~m}$ throughout the rest of the domain. Such high vertical resolution is likely to be necessary to properly resolve processes occurring in the TTL, such as the effect of gravity waves on the temperature structure (e.g. Kuang and Bretherton, 2004), and therefore likely on mixing processes too.

It has been demonstrated in previous CRM studies (e.g. Redelsperger et al., 2000), that the use of $2 \mathrm{~km}$ horizontal resolution is fine enough to simulate deep convection reasonably well. But, resolution can have a significant effect on convective mixing processes (e.g. Petch et al., 2002) and therefore may affect the turbulent mixing of overshoot air with the surroundings as well as the entrainment of environmental air into the rising air parcel in the boundary layer as observed in Carpenter et al. (1998). The latter would be likely to lead to clouds that are too vigorous due to a lack of dilution by environmental air from higher levels. These processes would require a resolution finer than $2 \mathrm{~km}$ to simulate explicitly (e.g. Lane et al., 2003, and Carpenter et al., 1998, use a horizontal grid spacing of $50 \mathrm{~m}$ ), although a sub-grid mixing parame- terisation is included in the model, which may represent this reasonably well. Also, the large ratio of horizontal to vertical grid size may have an unknown effect on the vertical mixing and might therefore affect the mixing of overshoot air in the TTL. In addition, Lane and Knievel (2005) suggest that model resolution affects the spectra of gravity waves formed by CRM models, which can affect whether waves break or not and hence whether mixing due to this process occurs. Further simulations to explore any potential sensitivities to resolution would be desirable, but were too computationally expensive for the current study.

Information on the various runs is displayed in Table 1. The "3D high CCN" case refers to a microphysical sensitivity test case that uses the same heating rates for cloud initiation as the "3-D" case and is described in Sect. 3.4. As the heating rate is decreased, the maximum vertical velocity, which is $50 \mathrm{~m} \mathrm{~s}^{-1}$ in the most vigorous case, reduces to only 39.3 and $28.4 \mathrm{~m} \mathrm{~s}^{-1}$, respectively, as the clouds became less intense. $50 \mathrm{~m} \mathrm{~s}^{-1}$ represents a very high updraught, but one that is within the range of those inferred from observations of tropical deep convection in other tropical regions (e.g. Simpson et al., 1993). The $10 \mathrm{dBZ}$ echotop also reduces in height with cloud intensity from a maximum of $18.2 \mathrm{~km}$ to a minimum of $16.4 \mathrm{~km}$ in the "3D-weak" case. Interestingly, the $40 \mathrm{dBZ}$ echotop is higher in the "3D-med" case than in the more intense cloud. However, examination of the timeseries of maximum echotop heights (not shown) reveals that heights above $14 \mathrm{~km}$ were attained only very briefly in the weaker case (one data point in the timeseries where points were calculated every $5 \mathrm{~min}$ ), whereas $14 \mathrm{~km}$ was reached by the $40 \mathrm{dBZ}$ contour for considerably longer in the " $3-\mathrm{D}$ " simulation (for three data points in the timeseries).

As a result of the heating, a maximum temperature perturbation of $7.2 \mathrm{~K}$ was produced in the " 3 -D" case, with smaller perturbations in the cases with the lower heating rates. Whilst this temperature increase is large, it is in line with previous studies of very deep convection where similar initiation methods were used. For example, maximum temperature perturbations of up to $8 \mathrm{~K}$ were produced in the study of Robinson and Sherwood (2006) where heating rates were applied for over an hour over a $100 \mathrm{~km}$ long area. A further indication of the vigour of the convection produced by the heating and moistening is given by the mean CAPE values for the different runs. These were calculated using the mean profiles over the heating area and are shown after the heating had been applied for $5 \mathrm{~min}$. Unfortunately, this data was only available every $5 \mathrm{~min}$ and hence the peak CAPE values may have been missed. The values show that the CAPE increased from the original value of $1095 \mathrm{~J} \mathrm{~kg}^{-1}$ up to 2449 $2687 \mathrm{~J} \mathrm{~kg}^{-1}$ in the $3-\mathrm{D}$ cases and up to $3064 \mathrm{~J} \mathrm{~kg}^{-1}$ in the 2 -D case. The increase was larger in 2-D since the number of points that are used in the average over the heating area is smaller. Whilst these increases are high, the CAPE values are still quite moderate compared to other studies (e.g. Chaboureau, 2007) and for the 3-D cases are close to the 
Table 1. Information on the different simulations. Columns are the maximum updraught; maximum radar reflectivity; the maximum height of the 10, 35 and $40 \mathrm{dBZ}$ echo tops; the maximum temperature and vapour perturbations in the lower $2.5 \mathrm{~km}$ of the domain; and the mean CAPE over the heating area after 5 min of heating.

\begin{tabular}{|c|c|c|c|c|c|c|c|c|}
\hline \multirow[t]{2}{*}{ Run } & \multirow{2}{*}{$\begin{array}{l}\text { Max } \\
\text { updraught } \\
(\mathrm{m} / \mathrm{s})\end{array}$} & \multirow[t]{2}{*}{ Max dBZ } & \multicolumn{3}{|c|}{ Max height of echotop $(\mathrm{km})$ : } & \multirow{2}{*}{$\begin{array}{l}\text { Max temp } \\
\text { perturbation } \\
\text { (K) }\end{array}$} & \multirow{2}{*}{$\begin{array}{l}\text { Max vapour } \\
\text { mixing ratio } \\
\text { perturbation } \\
\left(\mathrm{g} \mathrm{kg}^{-1}\right)\end{array}$} & \multirow{2}{*}{$\begin{array}{l}\text { Mean CAPE } \\
\text { over heating } \\
\text { area } \\
\left(\mathrm{J} \mathrm{kg}^{-1}\right)\end{array}$} \\
\hline & & & $10 \mathrm{dBZ}$ & $35 \mathrm{dBZ}$ & $40 \mathrm{dBZ}$ & & & \\
\hline $3-\mathrm{D}$ & 50 & 54.7 & 18.2 & 17.5 & 15.1 & 7.2 & 2.2 & 2687 \\
\hline $2-\mathrm{D}$ & 21.2 & 53.5 & 17 & 13.2 & 9.7 & 8.9 & 2.5 & 3064 \\
\hline 3-D-med & 39.3 & 56 & 17.4 & 16.5 & 15.6 & 4.1 & 3.2 & 2480 \\
\hline 3-D-weak & 28.4 & 55.2 & 16.4 & 15.3 & 11.7 & 3.3 & 4.2 & 2449 \\
\hline 3-D high CCN & 46.3 & 54.5 & 18.2 & 15.9 & 13.4 & 7.2 & 2.2 & 2687 \\
\hline
\end{tabular}

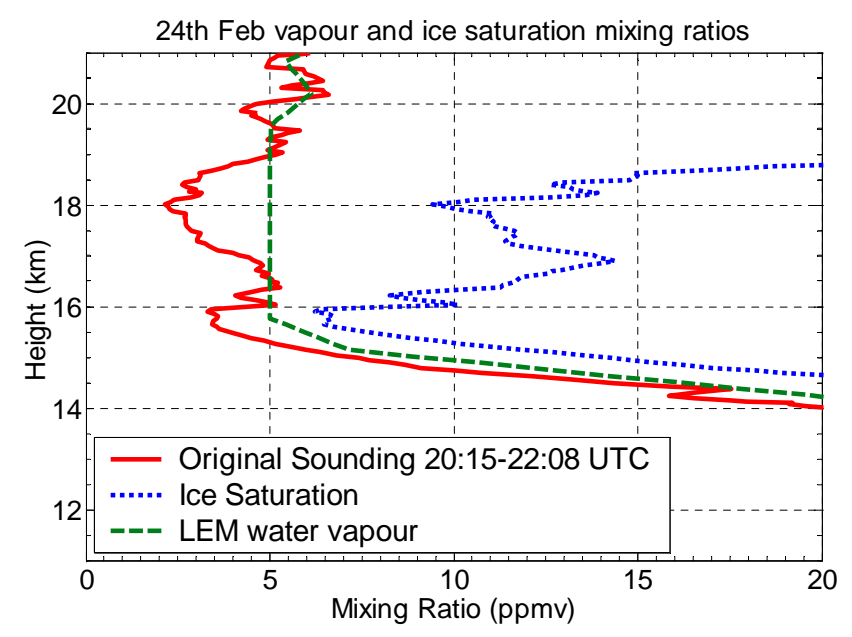

Fig. 4. Water vapour and ice saturation mixing ratio measurements from the 24 February sounding and the idealised vapour profile input into the LEM Cloud Resolving Model.

upper range of those predicted by the Meso-Eta mesoscale model.

The main purpose of these simulations is to study the effect of deep convection on the TTL water content. Therefore, in order to avoid the issue of determining whether reductions in total water were due to the ice deposition dehydration effect, or simply due to reversible advection from drier heights, the simulations were initialised with a constant vapour mixing ratio of $5 \mathrm{ppmv}$ around the TTL region, between the heights of 15.77 and $18.93 \mathrm{~km}$, as shown in Fig. 4. This means that any reductions in the total water in this region must have been due to the ice deposition dehydration effect and not reversible transport of the initial vapour field. The value of 5 ppmv corresponds to the approximate vapour mixing ratio in the sounding at the lower and upper boundary of this region and is in line with other measurements of the
TTL water vapour concentrations made at 22:00 UTC at the same location using the micro-SDLA instrument on board another balloon (Durry et al., 2006). This employs the diode laser absorption spectroscopy technique and hence is likely to be more accurate than standard radiosonde measurements, which used the Vaisala RS 80 package.

There are several different ways to define the TTL region, which is generally thought of as a transition zone containing air with both tropospheric and stratospheric properties. The main concern here is how convection affects the water vapour content of air that will enter the stratosphere at some point in the future and hence a useful definition for the TTL base is that of the net zero radiative level $\left(Z_{\mathrm{rad}}\right)$ as in Sherwood and Dessler (2000). Based on several different radiation models, Gettelman et al. (2004) found $Z_{\text {rad }}$ to be located at a mean height of $15 \mathrm{~km}$ in the tropics with differences due to time and space variations leading to a $\pm 500 \mathrm{~m}$ change, and intermodel variations giving changes of $\pm 400 \mathrm{~m}$. Whether this applies to the region of concern here, though, is unknown.

Since the main temperature inversion of the environment is located at $\sim 15.9 \mathrm{~km}$ (Fig. 4) and significant changes in the vertical gradient of the water vapour mixing ratio are apparent here, this height is likely to generally serve as an efficient mixing barrier to weaker vertical motions and hence if convection affects air above this height then it will be very likely to have a stratospheric effect. Therefore, this will be termed the tropopause in future discussions here. According to the radar echo top heights, convection was observed to penetrate the tropopause and so the top of the TTL might be considered to be somewhat higher than $15.9 \mathrm{~km}$, following the convention of Sherwood and Dessler (2000).

\subsection{Radar observations}

Radar statistics from the TroCCiBras/HIBISCUS field campaign (Held et al., 2006) show that, as in the "3-D" and "3Dmed" cases, the $40 \mathrm{dBZ}$ contour does reach $15 \mathrm{~km}$ and over in 
Table 2. Frequencies of echo tops in the height ranges indicated for cell tracks within the $240 \mathrm{~km}$ radius range of the IPMet radar in Bauru during the period from 21 January to 11 March 2004. Mean and max labels refer to the frequencies of the mean and maximum echo top of each track during the lifetime of the cell and 10, 35 and $40 \mathrm{dBZ}$ refer to the tops of radar reflectivity contours of these values. Only cells with a volume larger than $50 \mathrm{~km}^{3}$, based on the 10,35 and $40 \mathrm{dBZ}$ contours, are included in the statistics.

\begin{tabular}{lllllll}
\hline $\begin{array}{l}\text { Echo Top } \\
\text { (km a.m.s.l.) }\end{array}$ & \multicolumn{2}{c}{$\begin{array}{c}\text { Echo Tops } \\
10 \mathrm{dBZ}(\%)\end{array}$} & \multicolumn{2}{c}{$\begin{array}{c}\text { Echo Tops } \\
\text { 35 dBZ }(\%)\end{array}$} & \multicolumn{2}{c}{$\begin{array}{c}\text { Echo Tops } \\
\text { 40 dBZ (\%) }\end{array}$} \\
\hline & Mean & Max & Mean & Max & Mean & Max \\
\hline 4 & 0.2 & 0.18 & 0.36 & 0.36 & & \\
5 & 1.66 & 0.65 & 2.42 & 1.13 & & \\
6 & 20.63 & 6.32 & 11.19 & 4.03 & 3.45 & 0.13 \\
7 & 28.56 & 31.48 & 28.82 & 22.26 & 32.10 & 18.03 \\
8 & 21.01 & 11.87 & 30.84 & 15.54 & 35.68 & 18.03 \\
9 & 13.54 & 10.72 & 17.79 & 15.06 & 19.95 & 18.67 \\
10 & 8.07 & 16.46 & 6.24 & 23.63 & 6.14 & 25.70 \\
11 & 4.25 & 6.96 & 1.93 & 7.37 & 2.43 & 7.42 \\
12 & 1.45 & 5.63 & 0.28 & 4.43 & 0.26 & 5.88 \\
13 & 0.3 & 4.15 & 0.08 & 4.47 & & 5.50 \\
14 & 0.19 & 1.29 & 0.04 & 0.81 & & 0.51 \\
15 & 0.04 & 1.13 & & 0.52 & & 0.13 \\
16 & 0.03 & 1.94 & & 0.40 & & \\
17 & 0.04 & 0.48 & & & & \\
18 & 0.01 & 0.23 & & & & \\
19 & 0.01 & 0.22 & & & & \\
$\geq 20$ & 0.01 & 0.29 & & & \\
\hline
\end{tabular}

the Bauru area, albeit fairly infrequently. Table 2 shows the percentages of the mean and maximum radar echo tops for the 10,35 and $40 \mathrm{dBZ}$ reflectivity contours in certain height ranges, for cells where these contours contained storm volumes of $\geq 50 \mathrm{~km}^{3}$. They were derived using the TITAN Software and are based on radar "tracks", which is the term given to describe the following of a convective cell for its lifetime (including cell splits and mergers) by the software. A total of 10198,2484 and 782 cells were identified, using the 10,35 and $40 \mathrm{dBZ}$ threshold, respectively.

The data shows that the $40 \mathrm{dBZ}$ echo top of one cell $(0.13 \%$ of the 782 tracks) reached an absolute maximum height of $15-16 \mathrm{~km}$, with $0.64 \%$ (5 cells) exceeding $14 \mathrm{~km}$ during the 51 day observation period. In addition, the $35 \mathrm{dBZ}$ contour in the "3-D" case reached higher than any of the observed events during the campaign (Table 1) and its maximum height in the "3D-med" case $(16.5 \mathrm{~km})$ was consistent with only 10 observed events over the campaign. Therefore, based on these higher reflectivities, events as severe as those simulated in the "3-D" and "3D-med" case may represent the upper limit of the convective effect of cells in this area on the TTL region during the experimental period. However, the season in which the campaign took place was less active than previously observed seasons as based on lightning (Naccarato et al., 2004) and other observations (Pommereau et al.,
2007). Thus, clouds such as those modelled may have been more common in other years.

On the other hand, the maximum height reached by the $10 \mathrm{dBZ}$ contour in the " 3 -D" case $(18.2 \mathrm{~km})$ is consistent with 75 of the observed cells over the campaign. This suggests that the model may be predicting too many particles of high mass in the upper troposphere, but that the overall heights reached by the clouds are consistent with reality. In addition, factors such as the beam width divergence (beam width of radar $=2^{\circ}$ ) and the possibility of radar scans missing the peak development of clouds due to the time taken to complete a sweep $(\sim 7.5 \mathrm{~min})$, may result in the statistics not representing the higher altitude, high reflectivity contours as consistently as the output from the model.

Figure 5 shows a vertical cross-section through the storm complex at a time when it was quite mature and, in places, was almost $100 \mathrm{~km}$ wide at the altitude of $3.5 \mathrm{~km}$. It shows a $10 \mathrm{dBZ}$ echo top that reaches up to $\sim 15 \mathrm{~km}$. The cell shown is fairly typical of those that occurred on 24 February within the radar range. There is little tilt of the updraught core, indicating fairly weak shear up to the heights involved. This slice is compared to the simulated radar reflectivity for the various runs in the following sections. 


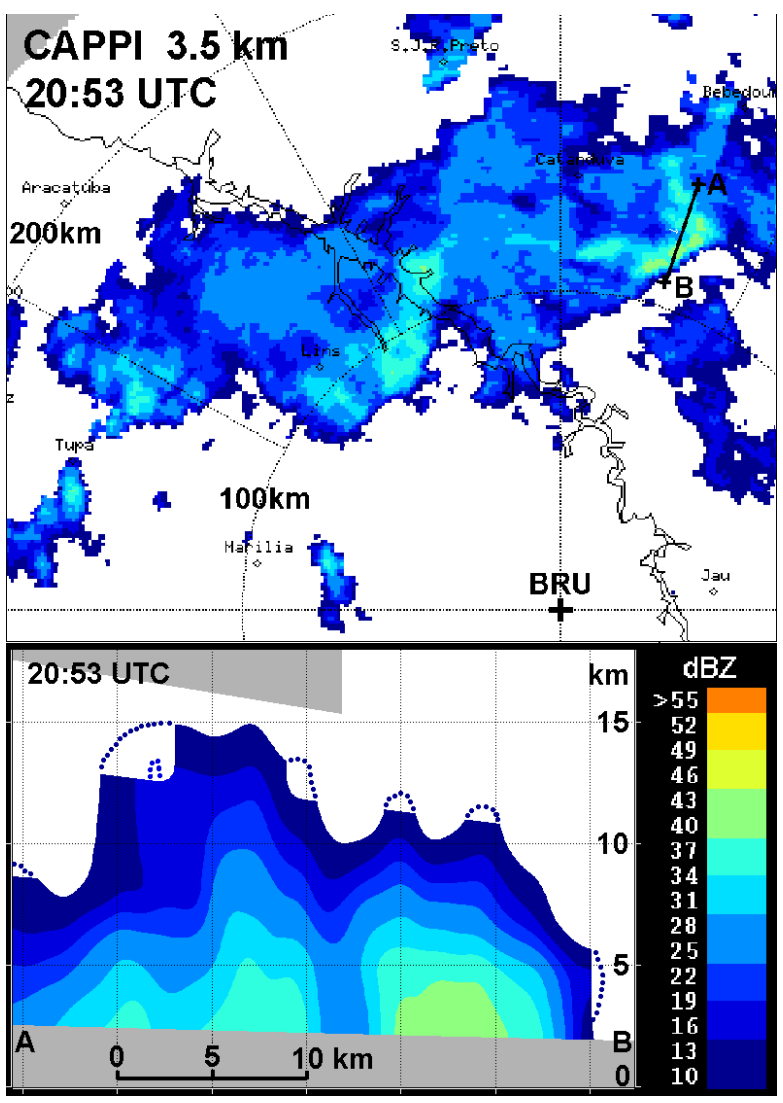

Fig. 5. CAPPI (Constant Altitude PPI at $3.5 \mathrm{~km}$ a.m.s.1.) of the multicelluar storm on 24 February 2004 at 20:53 UTC (top), indicating the base line of the cross-section shown on the bottom (gaps due to elevation stepping have been complemented by dotted lines for 10 and $20 \mathrm{dBZ}$ ).

\section{Model results}

\section{$3.13-\mathrm{D} / 2-\mathrm{D}$ comparisons}

Ideally, it would be possible to be able to simulate the effects of overshooting clouds on the TTL using 2-D models only, since the computational demand of 3-D simulations is huge in comparison. 2-D models have been shown to be able to reasonably simulate some convective systems (e.g. Redelsperger et al., 2000) but have not previously been compared with 3-D models in studies concerning the TTL. It is possible that aspects such as the mixing of the overshoot air with the TTL air and gravity wave production may be wrongly represented by 2-D simulations. The latter may have an effect on mixing processes through the breaking of the gravity waves near the TTL (e.g. Lane et al., 2003; Wang, 2003). The degree of mixing is important since it can increase the temperature of the overshoot air and hence may help to determine the final settling height of the detrained air as it sinks under its negative buoyancy. In addition, clouds overshooting into the TTL are likely to carry large amounts of ice with them and thus any mixing of this ice with the TTL air is liable to cause a potentially large moistening effect. In this section, results from a 3-D simulation are presented and compared to those from a similar 2-D case.

\subsubsection{General description of cloud features}

In response to the heating in the lower layers of the domain a convective thermal was generated that reached just below $18 \mathrm{~km}$ by $00: 35$.

Figure 6 is a horizontal cross-section of water vapour mixing ratio through the simulated $3-\mathrm{D}$ cloud at $16.5 \mathrm{~km}$ and $00: 35$, to give an idea of the location of the overshoot in the model domain. This height is already above the tropopause of the simulation environment and hence is likely to be within the TTL region. The effects on the water vapour are discussed shortly, but first of all the simulated radar reflectivities of a cross-section (dotted line in Fig. 6) through the cloud are examined and compared to the 2-D case in order to examine the general cloud features throughout the troposphere (Fig. 7).

The radar reflectivities, calculated every $5 \mathrm{~min}$, show that the initial stages of the overshoot were more vigorous and reached higher altitudes in the 3-D case compared to the 2-D one, despite the same heating and moistening rates being applied. For example, the $35 \mathrm{dBZ}$ contour has reached up to just under $17 \mathrm{~km}$ by 00:35 in the 3-D case, whereas it was only at $\sim 13 \mathrm{~km}$ in the $2-\mathrm{D}$ case. In addition, the $40 \mathrm{dBZ}$ reflectivity contour reached $15.1 \mathrm{~km}$ in one of the samples of the simulated cloud reflectivity in the 3-D case, which were calculated every $5 \mathrm{~min}$. By contrast, the $40 \mathrm{dBZ}$ contour of the $2-D$ case reached a maximum height of only $9.7 \mathrm{~km}$. This indicates increased flux of larger ice hydrometeors in the 3-D case compared to that of the 2-D case. After this time, the 2-D and 3-D cases show qualitatively similar clouds in terms of shapes and sizes, although in general the 2-D cloud was a little wider than that in the 3-D simulation. This is especially apparent for the last time shown, where the 2-D cloud also extended up to higher altitudes. The width of the clouds during the growth and decay phases was generally similar to the sizes of clouds observed by the IPMet radar suggesting that the warm and moist bubble used was producing a cloud of a realistic size.

In the $3-D$ case, the contours near $17 \mathrm{~km}$ at 00:35 are very closely spaced so that the $10 \mathrm{dBZ}$ contour is also close to this height, as it is in the 2-D case. The radar statistics in Table 2 show that 124 cells $(1.22 \%$ of 10198 cell tracks) had maximum echo tops of $\geq 17 \mathrm{~km}$, clearly overshooting the tropopause, which was generally around $16 \mathrm{~km}$ during the experimental period (Pommereau et al., 2007). Even though the majority of the clouds that overshot the tropopause during the campaign did not have $40 \mathrm{dBZ}$ echo tops as high as those simulated in the 3-D case, they may still have had a comparable impact on the TTL region since they are still likely to have transported a significant enough amount of ice 

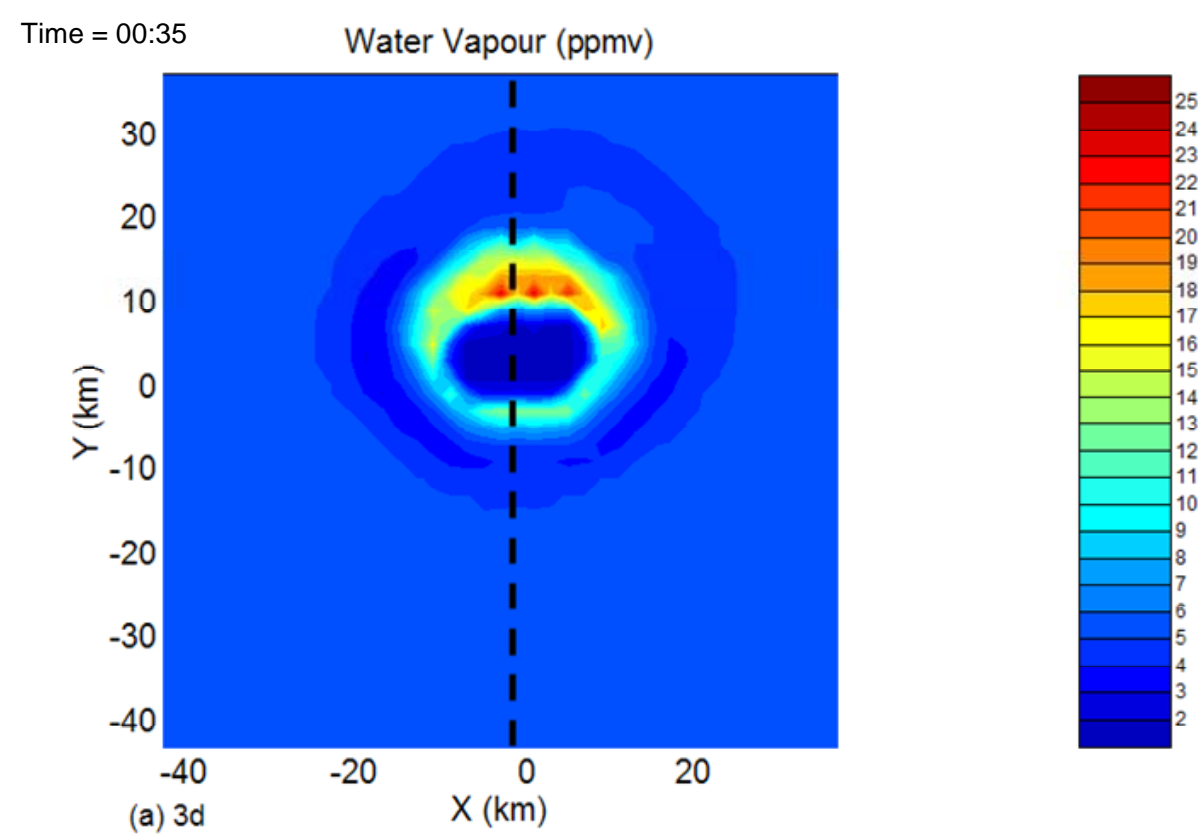

(a) $3 d$

Fig. 6. Horizontal cross-sections at a height of $16.5 \mathrm{~km}$ of the water vapour mixing ratio at $35 \mathrm{~min}$ of simulation time for the 3 -D case. The dotted line represents the location of vertical cross-section shown in the following figures.

to potentially have had an impact on the low water content of the TTL. Radar reflectivities of up to 54-55 dBZ were simulated in the interior of the cloud, which matched the maximum observed at similar heights by the IPMet radar on this day $(54 \mathrm{dBZ})$.

A comparison of the simulated storm structures with radar observations from this day yielded a reasonable agreement, as demonstrated in the vertical cross-section in Fig. 5. The horizontal and vertical extents of the cell, selected from the storm complex, are approximately the same magnitude as in the simulation, even including the distribution of the higher radar reflectivities (cell core).

The maximum updraught speeds of the clouds show significant variation between the 2-D and 3-D cases with the absolute maximum being $21 \mathrm{~m} \mathrm{~s}^{-1}$ at an altitude of $6.7 \mathrm{~km}$ for the former and $50 \mathrm{~m} \mathrm{~s}^{-1}$ at $12.5 \mathrm{~km}$ in the latter case. The increased vigour of the 3 -D case relative to the 2-D one suggests that some of the differences in the behaviour of the two overshooting clouds in the TTL that will be shown here, may be due to the increased mass flux and ice transport of the 3-D case. Further tests with less vigorous 3-D clouds are therefore examined later in order to determine whether or not this is the case.

3.1.2 The effect on TTL water content during the simulation

Figure 6 demonstrates that in the 3-D case the water vapour content at $16.5 \mathrm{~km}$ has been depleted significantly below the initial environmental value through cold temperature ice de- position. As well as the depleted vapour air formed in the core of the overshoot, though, considerable vapour increases have also occurred in the surrounding air, with values as high as 25 ppmv being reached. This time corresponds to that when the minimum vapour mixing ratio was achieved in the 3-D case (see Fig. 10).

The vertical slices (Fig. 8) show some similarities between the 3-D and 2-D cases with a similar size of overshoot disturbance and similar minimum values produced in both cases ( $0.57 \mathrm{ppmv}$ in 3-D and $0.62 \mathrm{ppmv}$ in 2-D). The area covered by the low vapour air is, however, significantly smaller in the 3-D case and there is a large area of high vapour content in the 3-D case that covers approximately half the area of the dehydrated air seen in the 2-D simulation. In addition, the boundary between the high vapour air below and the depleted vapour above is much more irregular in the 3-D case, indicating that more mixing due to small scale motions is occurring. Considerable amounts of ice were present in both cases (see contours in Fig. 8) in the same area as the overshoot air, allowing the possibility of significant moistening through sublimation of this ice and making this a likely explanation for the high vapour air that was seen in the 3-D case.

This idea is supported by the potential temperature field for these slices (Fig. 9), which shows that in the 3-D case warm high potential temperature air with values 380 to $400 \mathrm{~K}$ has been dragged downwards below $16 \mathrm{~km}$ and into the overshoot air from heights around $17 \mathrm{~km}$. The location of this air corresponds to the area of high water vapour described above and suggests that the warming due to its presence caused ice 

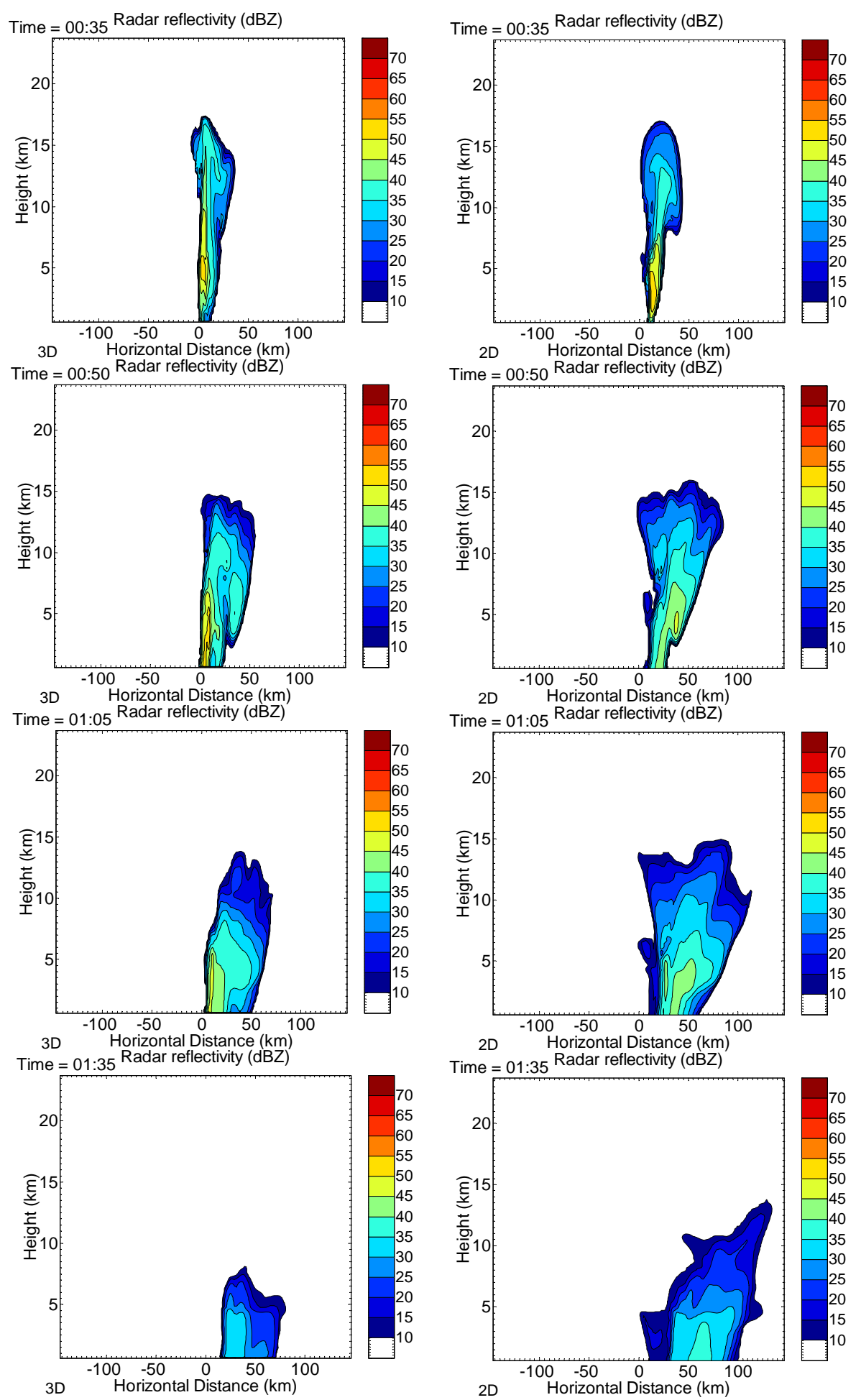

Fig. 7. Simulated radar reflectivity at various times for the 3-D (left) and 2-D (right) cases. The 3-D cross sections are taken through the line shown in Fig. 6. 


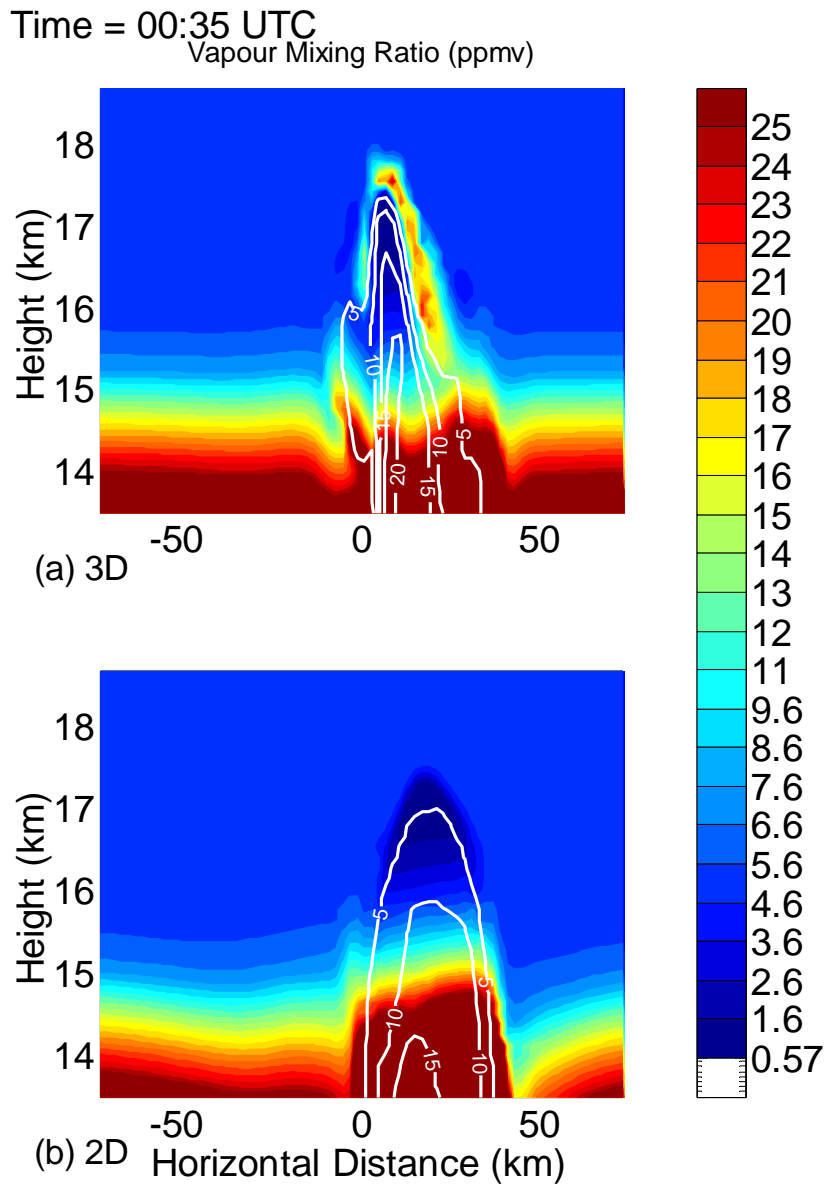

Fig. 8. Water vapour mixing ratio fields after $35 \mathrm{~min}$ of simulation time: (a) Cross section through the line indicated in Fig. 6 of 3-D simulation; (b) 2-D case. The white contours indicate the total ice mixing ratio (ice+snow+graupel) in $\mathrm{ppmv} \times 10^{3}$.

sublimation and was responsible for the large water vapour mixing ratio values produced. In the 2-D case such intrusion of high potential temperature air has not occurred, suggesting that the use of 3-D has a large impact on the mixing of the overshoot air with its surroundings.

Figure 10 shows the minimum water vapour mixing ratio achieved over each height and at each time $(5 \mathrm{~min}$ samples) in the 3-D and 2-D cases. It demonstrates that in the 3-D case lower vapour values are reached (a minimum of 0.2 ppmv compared to $0.6 \mathrm{ppmv}$ in 2-D) on account of the 3 -D case producing a more vigorous updraught, which leads to lower temperatures. These low values also occur at higher altitudes (height of minimum is $17.9 \mathrm{~km}$ in $3-\mathrm{D}$ and $17 \mathrm{~km}$ in 2-D), again symptomatic of the higher updraughts in the 3-D case. However, the low vapour values quickly disappear in the 3-D case so that after $\sim 50 \mathrm{~min}$ the minimum vapour value is $4.97 \mathrm{ppmv}$, which is very close to the initial minimum vapour mixing ratio of the TTL (5 ppmv). In the 2-D simulation, air that is significantly vapour depleted remains

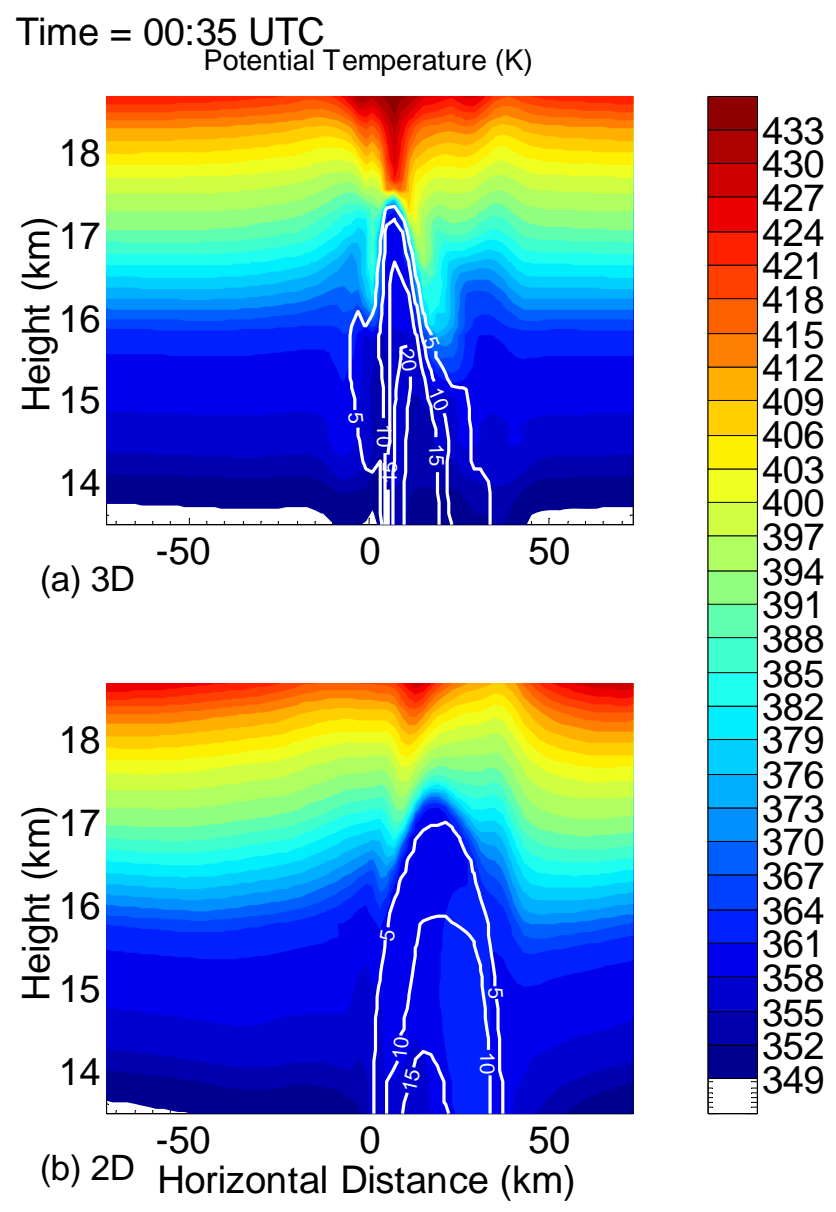

Fig. 9. As for Fig. 8, but for the potential temperature.

until the end of the simulation time, with the minimum being $3.3 \mathrm{ppmv}$ at that time. The persistence of the low vapour air allows time for the separation of the ice formed, to leave behind low total water air. This lack of ice is important in determining whether permanent dehydration is likely to occur since ice sublimation cannot then replenish the vapour of the air, which may otherwise happen as the cold air sinks and warms under its negative buoyancy, or through mixing with warmer surrounding air, as observed in the 3 -D case. The location of the ice as it sinks downwards is demonstrated by the total water time-height plot in Fig. 10 where the reduction in total water in 2-D can also be seen.

The cross section of the water vapour mixing ratio after $1 \mathrm{~h}$ 35 min (Fig. 11) reveals large differences between the 2-D and 3-D cases. The dehydrated air in the 2-D case is readily apparent, whilst in the 3-D case a plume of high vapour content air is the only observable feature in the TTL vapour field. A vapour plume has occurred in the 2-D case but this is very small in comparison to that in the 3-D case. Also demonstrated here are significant dynamical differences between the two cases. In 2-D there is a large wave like disturbance in the vapour field to the left of the plot, which is caused 

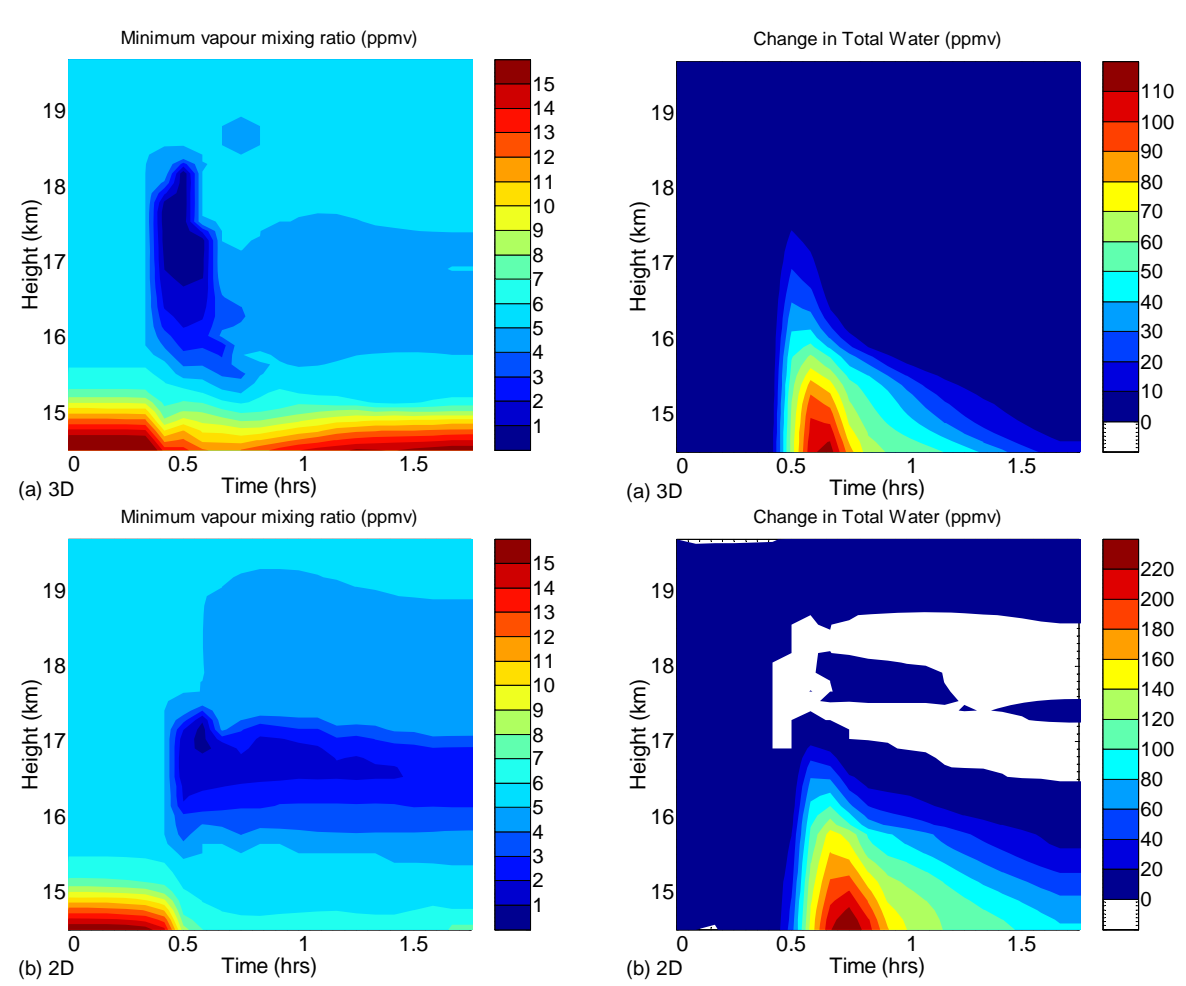

Fig. 10. Time-height plot of the minimum water vapour mixing ratio (left) and the domain mean total water (right) for; (a) The 3-D case; (b) the 2-D case.

by gravity waves that emanated from the cloud sides after the overshoot penetrated the stable layer of the tropopause. Similar waves appear on the other side, to the right of the area shown in Fig. 11 (not visible on the plot). Such waves did occur in the 3-D case, but with smaller displacements as demonstrated by Figs. 8 and 9.

The differences in the velocity magnitudes of the waves in the TTL between the 2-D and 3-D cases can be demonstrated by the maximum updraught velocities (not shown). Despite the initial overshoot updraught in the 3-D case being larger and extending to higher altitudes, the updraughts quickly dissipate to leave very little wave motion, whereas in the 2-D case the upwards velocities due to wave motions persist throughout the simulation.

These gravity waves were responsible for some vapour removal in the 2-D case, as indicated by the dry air formed above the crest of the wave in Fig. 11 and hence, the larger wave magnitudes seen in 2-D may be somewhat responsible for the perseverance of the low vapour air seen in this case, but not in 3-D. The bulk of the dehydrated air, though, was left over from the initial overshoot and hence the differences in the mixing occurring during this event were likely to have been the main cause of the 3-D/2-D differences. The large differences in gravity wave behaviour and the differences in mixing observed suggest that the 2-D version of the present model is not well suited to simulating overshoot dynamics.

\subsubsection{Overall effects at the simulation end}

By the end of the simulation, the once negatively buoyant air detrained by the overshoot has almost reached its level of neutral buoyancy again in both the 2-D and 3-D cases, as judged from potential temperature perturbations (not shown). The 2-D case exhibited the largest perturbations relative to the initial state, but those of the air detrained from the overshoot had a maximum negative perturbation of $\sim 5 \mathrm{~K}$, which was typical of the potential temperature from the region only $250 \mathrm{~m}$ below, indicating that this air would only go on to sink by this amount, or less. The 3-D case showed even smaller perturbations throughout the TTL. This suggests that the situation at the simulation end is likely to be representative of the permanent effect of the convection in the TTL, barring the longer term effects of processes not included in the model, such as radiative effects and the Brewer Dobson circulation.

Figure 12 shows the mean changes in total water and vapour for the 2-D and 3-D cases, at the end of the simulation. The fact that the minimum 3-D total water value is only just below the initial value and that these mean values, as well as the maximum values across the domain (not shown), are significantly higher than the initial profiles, demonstrates the tendency for moistening in the 3-D case. This is in contrast to the 2-D case, where plots of minimum total water profiles (not shown) reveal that parts of the domain are significantly 


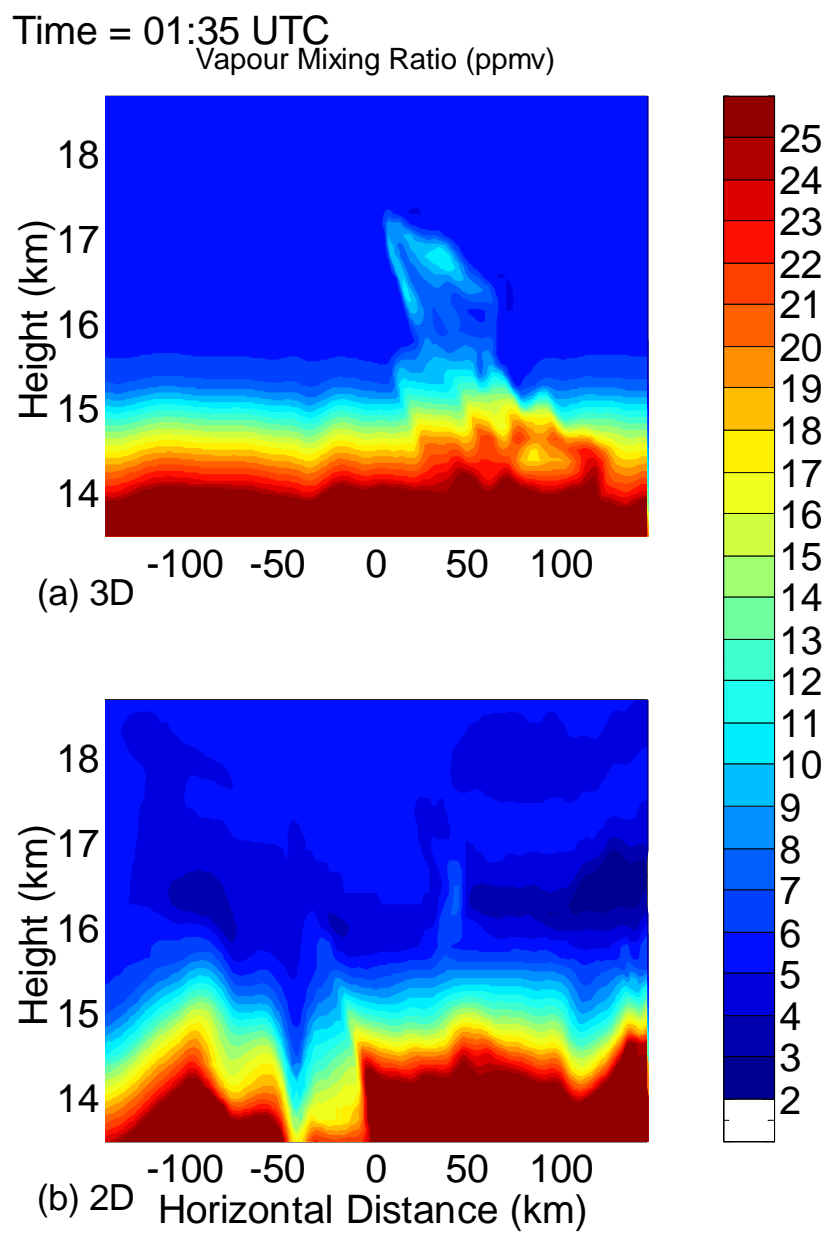

Fig. 11. As in Fig. 8, but for the time of 01:35.

depleted in total water with the overall mean total water being reduced above $15.84 \mathrm{~km}$. Below this height, however, the 2-D simulation causes a mean moistening of a magnitude that appears larger than in the 3-D case.

However, care must be taken in the comparison of the 2-D and 3-D means since the 2-D mean is taken over only one $300 \mathrm{~km}$ long 2-D slice, whereas in the 3-D case, the mean over 150 slices of width $2 \mathrm{~km}$ is taken, to give the average across the whole $300 \times 300 \mathrm{~km}$ domain. Since the horizontal cross section of the cloud outflow is roughly circular, the number of points in these slices that have been affected by the overshoot will reduce for slices further from the centre of the outflow. Therefore, the deviations of the 3-D mean from the background value will be "diluted" since more air with the background value is included in the summation. It can be shown that the mean changes along slices of the 3-D domain can be more significant than the changes observed in the 2-D case.

An attempt is made here to use the 3-D results to estimate how representative the mean changes across 2-D slices of the 3-D domain are of the full 3-D mean total water change at

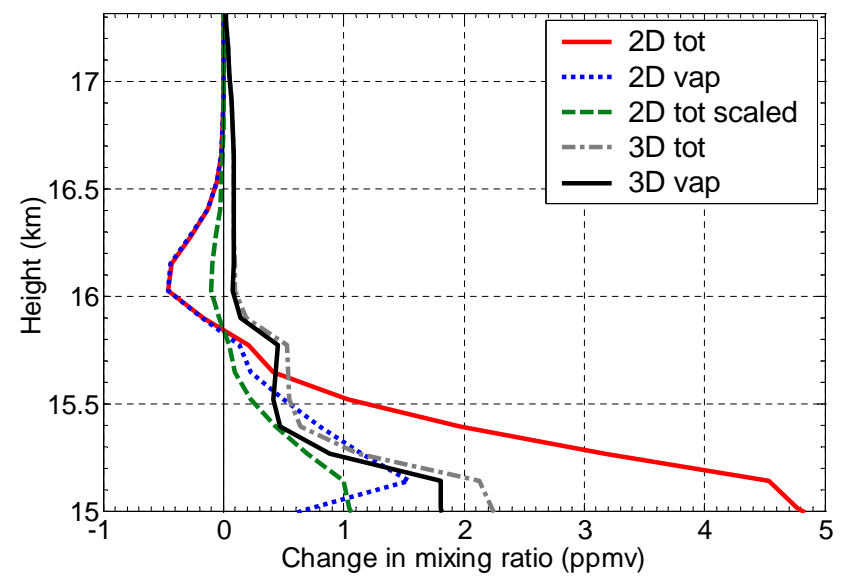

Fig. 12. The change in mean vapour and total water mixing ratios for the 2-D and $3-\mathrm{D}$ cases at the simulation end (time $=3 \mathrm{~h} 35 \mathrm{~min}$ ). In the 2-D case the mean is taken over the central $300 \mathrm{~km}$ of the overshoot area. "2-D tot scaled" refers to the mean 2-D change multiplied by a scaling factor of 0.22 to represent the likely overall $3-\mathrm{D}$ effect of such a 2-D slice if it represented just one slice out of a $300 \mathrm{~km} \times 300 \mathrm{~km}$ domain.

each height. This is done by assuming that the 2-D slice, from the 3-D simulation, showing the highest mean change at each height is representative of the 2-D simulation. The ratio of the mean change across this slice to the full mean change across the whole $300 \times 300 \mathrm{~km}$ area at that height then gives some indication of how much a 2-D change should be scaled by in order to better represent the change over a 3-D surface. This ratio of the mean change over the full 3-D area to that of the 2-D slice exhibiting the largest change, has an average value of 0.22 between 15 and $17 \mathrm{~km}$ based on the 3-D total water field at the end of the simulation. The 2-D mean total water changes shown in Fig. 12 are multiplied by this value for a fairer comparison to the 3 -D results (" $2-\mathrm{D}$ tot scaled" line). After scaling, the total water increases in the lower TTL become somewhat lower than in 3-D, indicating the importance of the consideration of the $2-\mathrm{D}$ results in a 3-D context.

For the 3-D case it can be seen that the increases in total water were mainly due to increases in water vapour, showing that little ice remains in the TTL region of this simulation. Therefore, there is little scope for this moistening to be removed by ice sedimentation, indicating that permanent moistening has likely occurred. In contrast, in the 2-D case most of the moistening that occurs below $15.84 \mathrm{~km}$ is due to ice and hence, there is the possibility that some of this ice would fall out over time and remove the excess total water. This may also be dependent on the differences in the ice size distributions between the 3-D and 2-D cases. Further discussion on ice size distributions is provided in Sect. 3.4 and in the conclusions. Increases in the vapour field of the 3-D case are apparent up to almost $17.5 \mathrm{~km}$, which is far above 


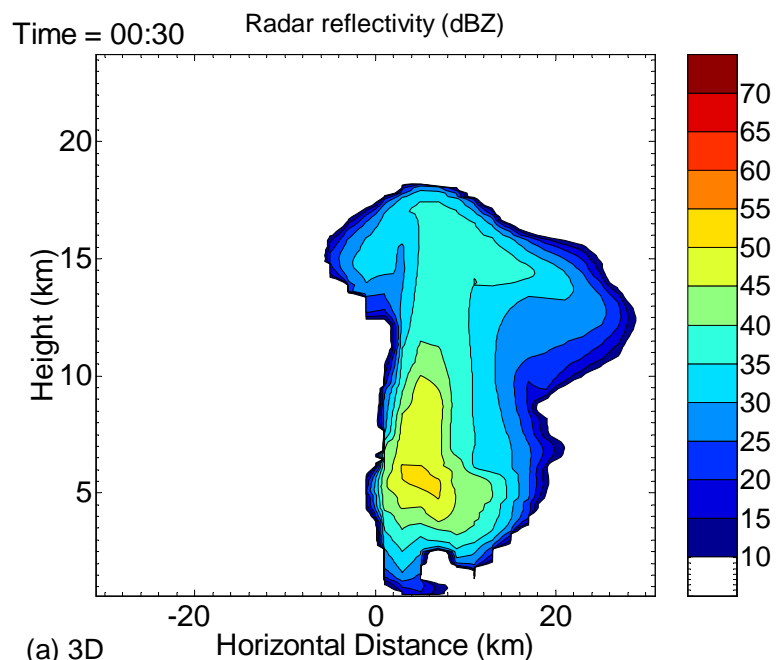

(a) 3D Horizontal Distance (km)

Time $=00: 35 \quad$ Radar reflectivity (dBZ)

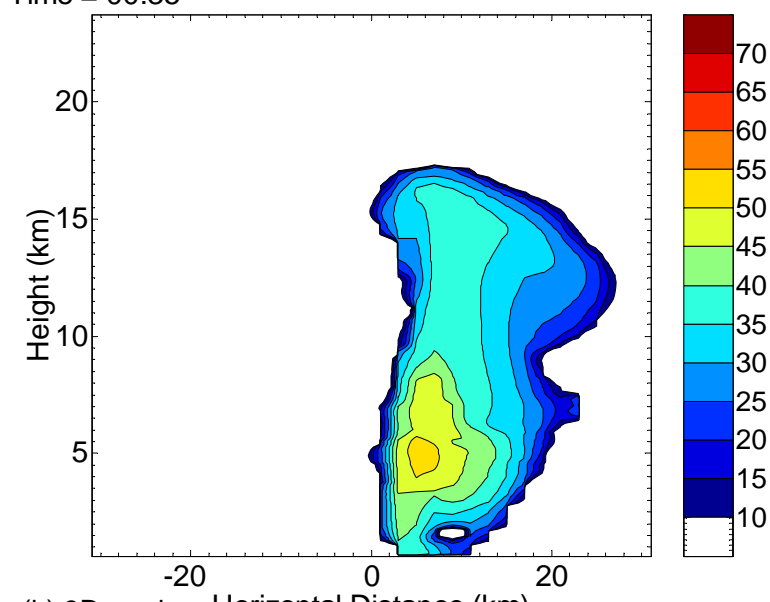

(b) 3D-med Horizontal Distance $(\mathrm{km})$

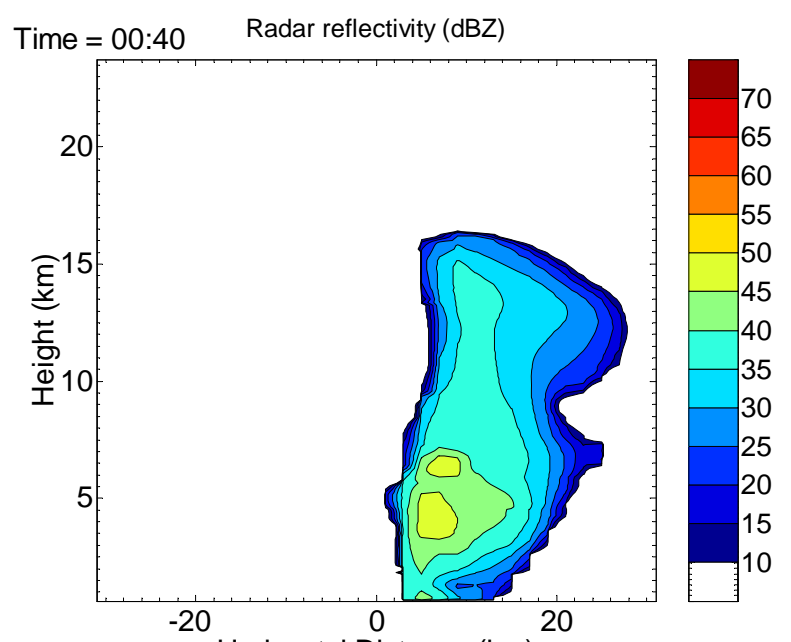

(c) 3D-weak Horizontal Distance $(\mathrm{km})$

Fig. 13. Cross sections of the simulated radar reflectivity of the 3-D cases of various strengths taken though the slice inidicated in Fig. 6. the tropopause $(15.9 \mathrm{~km})$, suggesting that direct moistening of the stratosphere has occurred here, although the increases at these high altitudes are much lower than those below the tropopause.

\subsection{Weaker 3-D cases}

It is possible that the extra mixing in the 3-D case that resulted in moistening of the TTL, rather than the dehydration seen in 2-D, may have been due to the increased vigour of the 3-D case relative to the 2-D one and hence, that a weaker storm in 3-D might also produce dehydration. In order to test this, less severe 3-D cases are examined here to look for any occurrence of dehydration. Table 1 reveals that the weaker cases generally had significantly lower maximum updraughts and maximum heights of the various simulated echo tops, but that the weakest case still had a $10 \mathrm{dBZ}$ echotop at $16.4 \mathrm{~km}$ and thus penetrated the tropopause.

Figure 13 shows cross sections of the simulated radar reflectivity for the different strength cases, taken at the times when the $10 \mathrm{dBZ}$ echo top reached its highest altitude in each separate case. These times were all different since the clouds took longer to develop when lower heating rates were applied. It shows that as the clouds become less intense, the radar echoes become narrower in the upper regions, which is more in agreement with the observed cross section from the case study day (Fig. 5). In addition, the $35 \mathrm{dBZ}$ echo contour is seen to reach successively lower heights, which is also more consistent with the observations. However, in general all the cases have simulated echoes in the upper regions of the cloud that are higher than those observed on the 24 February, 2004. For example, even in the weakest case, the $35 \mathrm{dBZ}$ echotop reaches around $15 \mathrm{~km}$, whereas in the observed cross section it only gets to $\sim 7 \mathrm{~km}$. Radar statistics for the whole campaign show that 23 events are consistent with the maximum height of the $35 \mathrm{dBZ}$ contour reached in the "3-D-weak" case, whereas as only 10 were consistent for the height reached in the "3-D-med" case and none for the "3-D" case. However, the height of the $40 \mathrm{dBZ}$ contour was consistent with 152 cells for the "3-D-weak" case, but only 1 cell for the "3-D-med" and "3-D" cases. The maximum heights of the simulated $10 \mathrm{dBZ}$ contours were in line with more of the observed storms; 322 for the "3-D-weak" and 124 for the "3-D-med" case.

These statistics do not strictly show how many events, of a similar nature to those simulated, actually occurred during the campaign since the majority formed on different days when conditions throughout the troposphere may have been different compared to 24 February. On the other hand, they are likely to give some idea of the range of severity of storms that occurred in the area and do suggest that cells such as that simulated in the "3-D-weak" case are likely to be more common in this area, with a tentative frequency of between 23 and 322 events over the 51 day observation period. However, the simulated maximum $10 \mathrm{dBZ}$ echotops of this case 
$(16.4 \mathrm{~km})$ and even of that of the strongest case $(18.2 \mathrm{~km})$ are considerably lower than that observed for a significant number of the observed cells, suggesting that some of the real clouds reached higher than those simulated, and that it may be inaccuracies in the model microphysics or the treatment used to calculate the radar reflectivites from the model fields that are leading to artificially high simulated radar reflectivities.

Most of the simulated reflectivity in the upper regions can be shown to be due to the graupel hydrometeor since the reflectivity is much larger for bigger particles. Such particles are likely to fall out quickly from the overshooting cloud and would evaporate more slowly upon mixing with stratospheric air. Therefore, their presence might indicate an underestimation of the amount of moistening that would occur in reality, assuming that the total mass of water transported to the upper cloud is accurate. If this is the case, it may be that the overall height reached by the cloud, which is perhaps better captured by the $10 \mathrm{dBZ}$ echotop, is more representative for estimating the number of real events that are likely to have had an effect on the TTL water content that is similar to those simulated. Then, comparisons of the high reflectivity contours may not be useful. On the other hand, increased amounts of graupel could indicate that too much water mass is being transported upwards by the cloud, perhaps due to a lack of removal by precipitation lower down or a lack on entrainment of dry air into the lower regions of the cloud caused by inaccuracies in the model dynamics. Further simulations and comparisons to observations are required to determine which is the case.

Figure 14 shows the mean vapour and total water change at the end of the simulation relative to the simulation start. It shows that, in all cases, moistening is observed and since the weakest cloud here has little effect at the altitudes where the dehydration was observed in 2-D and since the $10 \mathrm{dBZ}$ echotop is lower than that for the 2-D cloud, it suggests that a weaker still cloud would be unlikely to produce dehydration at similar altitudes to that observed in the 2-D cloud. Therefore, it seems likely that it was the 3-D dynamics that allowed extra mixing, rather than the increased severity of the 3-D case. Plots of the minimum vapour mixing ratio, similar to Fig. 10a (not shown), reveal similarly rapid removal of the low vapour air via mixing.

The amount of moistening reduces significantly with the intensity of the cloud, as might be expected, since there will be less upwards mass flux of ice with the lower updraught clouds. Above $16 \mathrm{~km}$, there is very little ice mass remaining in any of the cases. Between here and $17 \mathrm{~km}$, the average increases in the vapour mixing ratio are $0.30,0.092$ and 0.013 ppmv in the "3-D", "3-D-med" and "3-D-weak" cases, respectively. Between 15 and $16 \mathrm{~km}$, the mean increases are, in the same respective cases, $1.0,0.83$ and $0.76 \mathrm{ppmv}$. In this lower region there is only significant ice remaining in the " 3 D" case, which allows the possibility of vapour increases in this case through evaporation of this ice in the future.

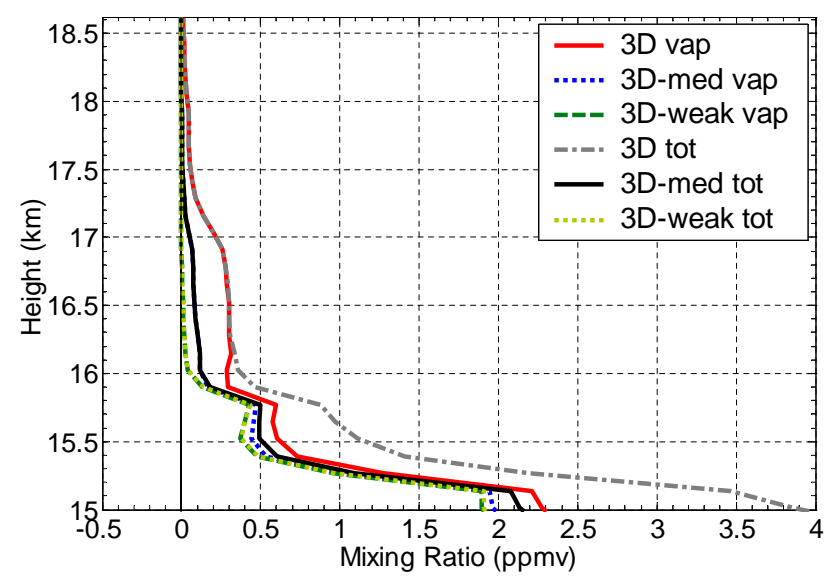

Fig. 14. The change in mean vapour and total water mixing ratios, at the simulation end, for the various 3-D cases. Means are taken over the central $150 \mathrm{~km}$ of the domains.

3.3 Assessing the potential global significance of the TTL water effects

In order to put the changes seen in the above cases into context in terms of a global stratospheric effect, the mechanism by which the air affected by the clouds is likely to be transported into the stratosphere must be considered. The process assumed here is similar to that envisaged by Sherwood and Dessler (2001), whereby air is horizontally processed through regions of frequent deep convective activity, which affect the TTL water content. Net lofting of the air above the net zero clear sky radiative lifting level $\left(Z_{\text {rad }}\right)$ is then assumed to mainly occur outside of the convective regions.

A rough estimate of the effect on a parcel of air moving through such a convective area is made by assuming that all convective events behave in the same way as those simulated and that their effect is spread evenly across the area. If there are $d N / d t$ events per unit area and each changes the total water mixing ratio of a region of air of area $A=150 \times 150 \mathrm{~km}^{2}$ and thickness $H$ by $d q$, then the overall change in total water mixing ratio of the parcel is approximately given by

$d Q=A \frac{d N}{d t} d q \tau$

where $\tau$ is the amount of time spent in the area. $\tau$ is approximated by the length of the convective area divided by the speed at which the parcel travels through it. A typical horizontal wind speed at TTL height is $5 \mathrm{~m} \mathrm{~s}^{-1}$ (e.g. Holton and Gettelman, 2001) and the size of a region of high convective activity, such as that occurring over South America, might be $\sim 2000 \mathrm{~km}$ or more based on the areas of frequent overshooting clouds identified by satellite observations in Liu and Zipser (2005). This would give a $\tau$ value of $\sim 4.6$ days.

$d N / d t$ is estimated from the TroCCiBras/HIBISCUS radar statistics (Table 2) using the number of cell tracks whose maximum echo top heights were consistent with the 
Table 3. $d Q$ values (Eq. 1) for the different runs. These were made based on the observed numbers of cell tracks whose maximum echo top heights were consistent with the simulated maximum echo top (from Table 2), for reflectivity thresholds of 10,35 and $40 \mathrm{dBZ}$. $d q$ values based on averages of vapour changes only, over both $15-16 \mathrm{~km}$ and $16-17 \mathrm{~km}$, are used.

\begin{tabular}{|c|c|c|c|c|c|c|}
\hline \multirow[b]{2}{*}{ Run } & \multicolumn{2}{|c|}{$\begin{array}{l}\text { Based on echo tops of: } \\
10 \mathrm{dBZ} \\
\text { Mean } d Q \text { (ppmv) over: }\end{array}$} & \multicolumn{2}{|l|}{$35 \mathrm{dBZ}$} & $40 \mathrm{dBZ}$ & \multirow[b]{2}{*}{$16-17 \mathrm{~km}$} \\
\hline & $15-16 \mathrm{~km}$ & $16-17 \mathrm{~km}$ & $15-16 \mathrm{~km}$ & $16-17 \mathrm{~km}$ & $15-16 \mathrm{~km}$ & \\
\hline 3-D & 0.85 & 0.26 & 0 & 0 & 0.012 & 0.0034 \\
\hline 3D-med & 1.17 & 0.13 & 0.093 & 0.01 & 0.0095 & 0.0011 \\
\hline 3D-weak & 2.8 & 0.047 & 0.2 & 0.0034 & 1.3 & 0.022 \\
\hline 3D high $\mathrm{CCN}$ & 0.98 & 0.28 & 0.3 & 0.085 & 0.63 & 0.18 \\
\hline
\end{tabular}

simulated echo top heights for the 10,35 and $40 \mathrm{dBZ}$ reflectivity contours. These numbers were divided by the 51 days over which observations were made and by the area of the IPMet radar range (circle of radius $240 \mathrm{~km}$ ) to give an average frequency per unit area. The value of $d q$ for a height range was estimated from Fig. 14 using the increases in vapour only. The height of $Z_{\text {rad }}$ is critically important in the calculation, since the lower it is, the more moist air from below the tropopause is likely to be lofted into the stratosphere.

One estimate of $d q$ is made using the height of $15 \mathrm{~km}$ for $Z_{\text {rad }}$ (Gettelman et al., 2004) and by averaging over an arbitrary height of $1 \mathrm{~km}$. The thickness of the air parcel chosen for this average becomes important when considering how often air, on its way into the stratosphere, would have to pass through a convective region so that a constant supply of air affected by convection entered the stratosphere. With a typical ascent rate of just over $1 \mathrm{~km} \mathrm{month}^{-1}$ (e.g., Holton and Gettelman, 2001) all the air parcels in the $1 \mathrm{~km}$ region would need to be affected by convection approximately every month, if the $d Q$ value estimated here is to apply to the stratospheric entry mixing ratio of air. However, an estimation of the frequency that trajectories on the way into the stratosphere sample convective regions is beyond the scope of this study. The moistening estimates given here are intended to give a rough idea of the effect on $1 \mathrm{~km}$ deep air parcels as they make one traverse through a convective region and not on the overall stratospheric effect.

$d q$ values for the height range $16-17 \mathrm{~km}$ are also made since the air here is above the tropopause and therefore moistening at these heights would be almost certain to have a stratospheric effect. $d Q$ values based on the different height ranges and convective frequencies are presented in Table 3 for the three different 3-D cases. Water vapour, rather than total water, was used since it is possible that the remaining ice will sediment to below $15 \mathrm{~km}$ and hence not cause permanent moistening.

The results suggest that the moistening observed above the tropopause, between 16 and $17 \mathrm{~km}$, is only likely to significantly affect air on its way into the stratosphere if events, such as those simulated here, occur with a frequency on a par with those observed to have $10 \mathrm{dBZ}$ echo tops as high as those simulated; i.e., if the height of the $10 \mathrm{dBZ}$ echo top is indicative of the likely moistening potential of a cloud. This is possible since even clouds with $10 \mathrm{dBZ}$ radar reflectivities in the upper regions are still likely to transport amounts of water mass that are large enough to significantly affect the relatively dry TTL and stratosphere. In the case that the $10 \mathrm{dBZ}$ echo tops are representative of a similar moistening to that simulated, and if convection is only likely to affect the stratosphere if it moistens air above $16 \mathrm{~km}$, the result from the vigorous " 3 -D" case suggests that a $1 \mathrm{~km}$ deep layer of air might have its mixing ratio increased by $\sim 0.26 \mathrm{ppmv}$ when travelling though the convective region for 4.6 days. The predicted moistening in the "3-D-med" case is half this value. Both of these suggest a potentially fairly significant moistening of stratospheric air due to convection.

If air above $15 \mathrm{~km}$ is lofted into the stratosphere via the Brewer Dobson circulation, then much more moistening is likely. The most moistening is predicted for the "3-D-weak" case, since the heights of the various simulated echo tops were consistent with more of the observed clouds. For this case, $d Q$ values of up to 2.8 ppmv are predicted when based on $10 \mathrm{dBZ}$ echo top statistics. Such a moistening would be highly significant as it represents a large fraction of the stratospheric water vapour mixing ratio. However, because the simulated $35 \mathrm{dBZ}$ echo top was consistent with a lot fewer of the observed clouds and since the height of $Z_{\text {rad }}$ is uncertain, it is possible that this is an overestimate. Indeed, if the cloud frequency consistent with the simulated $35 \mathrm{dBZ}$ echo top height is used, a more moderate moistening of 0.2 ppmv is predicted for the "3-D-weak" case. For the other cases, very small moistening values of less than 0.012 ppmv are calculated when using either the $35 \mathrm{dBZ}$ consistent frequencies or the $40 \mathrm{dBZ}$ consistent ones, reflecting the tendency for those simulations to overestimate the reflectivity in the upper regions of the cloud.

As mentioned, the air below $16 \mathrm{~km}$ would have to be moved upwards by the Brewer Dobson circulation in order to affect the stratosphere. This would generally operate at latitudes slightly lower than those where the simulations were 
based, hence meaning that the air would have to travel equatorwards before this was possible. Even if this does occur the air is likely to be below the local cold point and hence will have to ascend through it to reach the stratosphere. This may result in dehydration of the moistened air and may therefore reduce the impact of the convective moistening on the stratosphere for the air below the Bauru tropopause. However, since air at the cold point can often be sub-saturated there is potential for moisture transported up to below the cold point to play some role in increasing the moisture content of air entering the stratosphere, relative to that which would have crossed the cold point had the convection not occurred.

Overall, the results suggest that the issues of whether air below the tropopause is likely to affect the stratosphere later on and whether clouds with similar $10 \mathrm{dBZ}$ echo tops to those simulated will have a similar stratospheric moistening to that predicted by the simulations, despite generally having lower echo tops for the higher reflectivity contours, will be key in predicting the stratospheric effect of convective clouds based on these and other CRM simulations.

\subsection{Microphysical considerations and CCN sensitivity}

The ice content and size distribution of the ice in the overshoot are likely to be key to determining the fall speed of the ice and hence at what rate it separates from the low vapour content air. Lower fall speeds will allow more ice evaporation upon mixing with the surrounding air and could result in a moistened TTL, whereas higher sedimentation rates may allow the majority of the ice to separate from the vapourdepleted air before mixing can occur and lead to dehydration of the TTL. It will be shown in this section that the ice mass and number concentrations in the overshooting air of these simulations are largely determined by microphysical processes occurring in the mid-troposphere, which therefore are likely to have an important effect on how an overshooting cloud affects the TTL water content. Increases in the aerosol loading of a cloud are known to affect cloud microphysics significantly through the activation of more $\mathrm{CCN}$ into water droplets at cloud base (e.g., Rosenfeld and Woodley, 2000) and hence the results from the previous section might be expected to be sensitive to this. This is explored using the same set up as in the "3-D" simulation described above, except a smaller horizontal domain of $150 \times 150 \mathrm{~km}$ is used.

In the CRM used in these studies, $\mathrm{CCN}$ variation is simulated through the warm rain process and the homogeneous freezing parameterisations. The model employs the Kessler (1969) warm rain parameterisation with modifications following Swann (1996). In this scheme, the increase in rain mixing ratio due to conversion from cloud droplets is proportional to the liquid water mixing ratio above a threshold value. No conversion occurs below this threshold mixing ratio, which is that of a population of $n_{L}$ droplets of diameter $20 \mu \mathrm{m}$. This number is assumed constant throughout the cloud and is varied to simulate the effect of changes in $\mathrm{CCN}$.
So, references to $\mathrm{CCN}$ number here refer to $\mathrm{CCN}$ that activate to form droplets. Increasing the value of $n_{L}$ has the effect of increasing the threshold cloud liquid mixing ratio and thus delaying the onset of rain formation by auto-conversion.

Increased droplet numbers allow more ice crystals to form when they freeze homogeneously at around $-38^{\circ} \mathrm{C}$. The number of ice crystals produced is proportional to the mass of liquid that freezes, but with the number formed per kilogram of air limited below the number of droplets per kilogram of air at cloud base. This is approximately equal to the input $\mathrm{CCN}$ number per cubic centimetre, as the air density is close to unity at cloud base. This means that fewer ice crystals per cubic centimetre can form at the low air densities of the upper troposphere than the input concentration of droplets per cubic centimetre.

Although this is an approximation, aircraft observations from Rosenfeld and Woodley (2000) suggest that large ice crystal number concentrations do indeed freeze homogeneously as a result of large droplet numbers at cloud base. They found that $\sim 200-400 \mathrm{~cm}^{-3}$ ice crystals were formed in the homogeneous freezing zone from droplet numbers of up to $\sim 800-1000 \mathrm{~cm}^{-3}$ in the lower troposphere. Similar numbers were also produced using a CRM with explicit microphysics in Khain and Pokrovsky (2004). At the air density of $0.4 \mathrm{~kg} \mathrm{~m}^{-3}$ at $-38^{\circ} \mathrm{C}$, as based on the sounding used in the simulations here, this ice crystal number concentration corresponds to $500-1000 \mathrm{~kg}^{-1}$, suggesting that the assumption in the high CCN case of ice crystal numbers at the homogeneous freezing level being limited to the same number of droplets per kilogram of air as at cloud base may be valid.

The default value of $n_{L}$, as used in the previous simulations, is $240 \mathrm{~cm}^{-3}$; for this sensitivity test this is increased to $960 \mathrm{~cm}^{-3}$. The activation of droplets of concentration $240 \mathrm{~cm}^{-3}$ is a fairly low number, more typical of maritime than continental conditions for the magnitudes of updraught speeds simulated here, whereas concentrations of $960 \mathrm{~cm}^{-3}$ are more associated with a continental environment (e.g., Twomey, 1959).

Figure 15 shows that, up to the end of the simulation, the most dominant source of total ice (cloud ice, snow and graupel combined) number concentration at heights up to $17 \mathrm{~km}$ is, in both CCN concentration cases, from the advection of ice. This can be seen to have formed mainly below the TTL region at $10-12 \mathrm{~km}$ (see the "Microphysics" profile in Fig. 15). This formation was due to the homogeneous freezing of cloud droplets, suggesting that this process is likely to be key to determining the ice size distribution of the overshoot. The increase in $\mathrm{CCN}$ number is seen to cause a large increase in the number of ice particles formed due to this process, since the more numerous droplets form more ice particles when they freeze. This results in more ice particles being advected up into the TTL, so that the mean ice number concentrations between 16 and $17 \mathrm{~km}$, at the end of the simulation, were $1.1 \times 10^{5}$ and $6.5 \times 10^{5} \mathrm{~kg}^{-1}$ in the normal and 
Table 4. Mean moistening between the simulation start and end, over the $150 \times 150 \mathrm{~km}$ domain and over both the $15-16$ and $16-$ $17 \mathrm{~km}$ height ranges. Results are shown for the normal $\left(240 \mathrm{~cm}^{-3}\right)$ $\mathrm{CCN}$ concentration and the high $\left(960 \mathrm{~cm}^{-3}\right) \mathrm{CCN}$ runs, along with the percentage increase of the high $\mathrm{CCN}$ case relative to the normal case.

\begin{tabular}{llll}
\hline & $\begin{array}{l}\text { norm CCN } \\
\text { (ppmv) }\end{array}$ & $\begin{array}{l}\text { high CCN } \\
\text { (ppmv) }\end{array}$ & $\begin{array}{l}\% \text { increase in } \\
\text { moistening for } \\
\text { high CCN }\end{array}$ \\
\hline $15-16 \mathrm{~km}$ vap & 1.03 & 1.16 & 12.6 \\
$15-16 \mathrm{~km}$ tot & 1.74 & 4.04 & 132.2 \\
$16-17 \mathrm{~km}$ vap & 0.297 & 0.336 & 13.1 \\
$16-17 \mathrm{~km}$ tot & 0.31 & 0.414 & 33.6 \\
\hline
\end{tabular}

high CCN cases respectively, with larger differences apparent at lower heights.

The effect of CCN on the TTL ice mass content manifests itself though a different microphysical pathway. More ice mass reaches the TTL in the higher CCN case (see "Change" profile in Fig. 16), but the excess mainly comes from increased ice formation below the homogeneous freezing zone in the region between 7 and $11 \mathrm{~km}$ (see "Microphysics" profile) with the majority attributed to more collisional accretion of liquid water by snow hydrometeors (not shown). This can occur because a reduction in the warm rain process in the high CCN case allows an increased mass of liquid water to be transported up to this region of the cloud. The same lack of warm rain is responsible for the lower amount of ice formation in the narrow region just below here, since the difference is due to less graupel formation through collisions of ice with rain.

This increased removal of liquid water mass between 7 and $11 \mathrm{~km}$ in the high CCN case means that there is little difference in the mass that is frozen homogeneously at $-38^{\circ} \mathrm{C}$ in the high $\mathrm{CCN}$ case, but the higher number of parameterised droplets that freeze result in more ice crystal numbers being formed by this process and subsequently carried into the TTL.

The profiles of the vapour and total water changes (Fig. 17) show that the increase in $\mathrm{CCN}$ leads to increases in the total water at all the heights shown. Above $\sim 16.4 \mathrm{~km}$, this increase mainly consists of increases in water vapour rather than ice, showing that virtually no ice mass remains at these heights and hence allowing for no possible further moistening by ice evaporation. Below $16.4 \mathrm{~km}$, larger increases in the total water are apparent in the high CCN case and the contribution of the ice relative to that of vapour starts to become larger, so that in the lower regions of the height ranges shown, it is increases in the former that account for the majority of the mean total water change. Whether the extra ice evaporates or has time to fall out before being lofted into the stratosphere, will therefore play a large role in determining
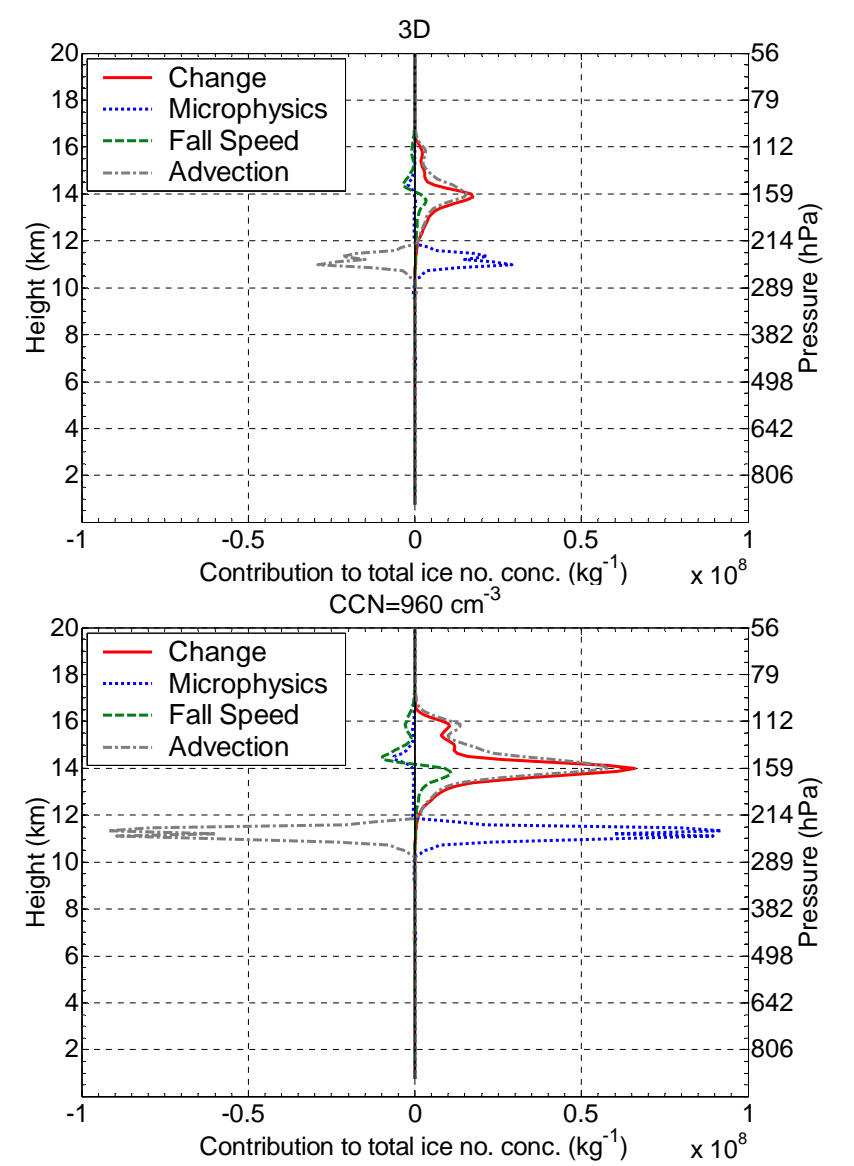

Fig. 15. Contributions from various processes to the change in the domain mean total ice number concentration (labelled "Change") from the simulation start up to its end. The processes are the microphysical formation of ice number, ice changes due to its fall speed and the advection of ice. Profiles are shown for the original simulation with a CCN concentration of $240 \mathrm{~cm}^{-3}$ (top) and also with a CCN concentration of $960 \mathrm{~cm}^{-3}$ (bottom).

the degree of moistening occurring in the lower TTL in both the low and high CCN runs.

Table 4 summarises the differences in moistening between the normal and high $\mathrm{CCN}$ cases. Moderate increases of $\sim 13 \%$ in the moistening due to vapour increases are apparent in the high $\mathrm{CCN}$ case, relative to the normal CCN run, for both height ranges indicated. However, much larger increases occur in the total water for the high $\mathrm{CCN}$ case with a $34 \%$ increase in moistening in the $16-17 \mathrm{~km}$ height range and a very large $132 \%$ increase for the $15-16 \mathrm{~km}$ range. Therefore, in the case where the remaining ice evaporates before sedimentation, a large sensitivity to moistening from $\mathrm{CCN}$ is predicted, especially if air below $16 \mathrm{~km}$ is lofted into the stratosphere.

The effect of the increasing $\mathrm{CCN}$ on the ice particle size distribution is demonstrated by Fig. 18a, which shows the mode diameter of the size distribution for the mixing ratio 


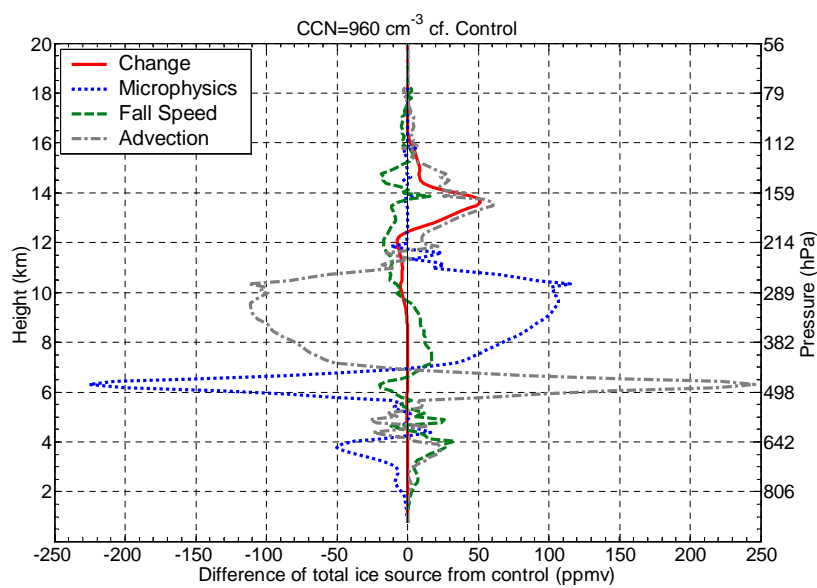

Fig. 16. Differences between the normal and high CCN cases. Differences are shown for the total ice mixing ratio at the simulation end (labelled "Change" in the legend) and for the contributions to the ice from the other processes indicated in the legend.

of the total ice at $16.15 \mathrm{~km}$. This height was chosen as it was above the tropopause, but plots at other heights show the same effect of a smaller mode diameter with increased CCN throughout most of the simulation, due to the larger ice number concentrations produced. The mode diameter decreases with time as the larger ice particles are removed by sedimentation, reaching $\sim 15$ microns in diameter by the end of the simulation.

Since the mode diameter is seen to be reducing at a slower and slower rate by this time and as the small ice will have a very low fall speed, it seems likely that the remaining ice at this height will sediment at a slow rate and may therefore have time to evaporate before doing so, either by radiative warming, as suggested in Holton et al. (1995), or through warming by mixing with the environment. Figure $18 \mathrm{~b}$ reveals that by the end of the simulation the mode diameter values are quite similar in both cases and are less than $25 \mathrm{mi}-$ crons for heights above the tropopause, again suggesting that moistening of the TTL due to this ice is quite likely.

However, simulations with an interactive radiation model that are performed for longer time periods are required in order to determine the fate of this ice in the high CCN simulation, but this is beyond the scope of the current study. Having said this, the results here show that $\mathrm{CCN}$ increases are likely to increase the residence time of ice in the air detrained by overshoots, which will therefore give the ice more chance to evaporate, making increased moistening more likely.

The simulated radar reflectivity in the high $\mathrm{CCN}$ case varies fairly significantly relative to the standard "3-D" case. Figure 19 shows a vertical cross section with the same orientation as those shown in Fig. 7. It reveals that the contours of the higher reflectivities (e.g., 35-40 dBZ) do not reach as high as in the normal CCN case, in which the same heating for cloud initiation was applied. Table 1 ("3-D high CCN"

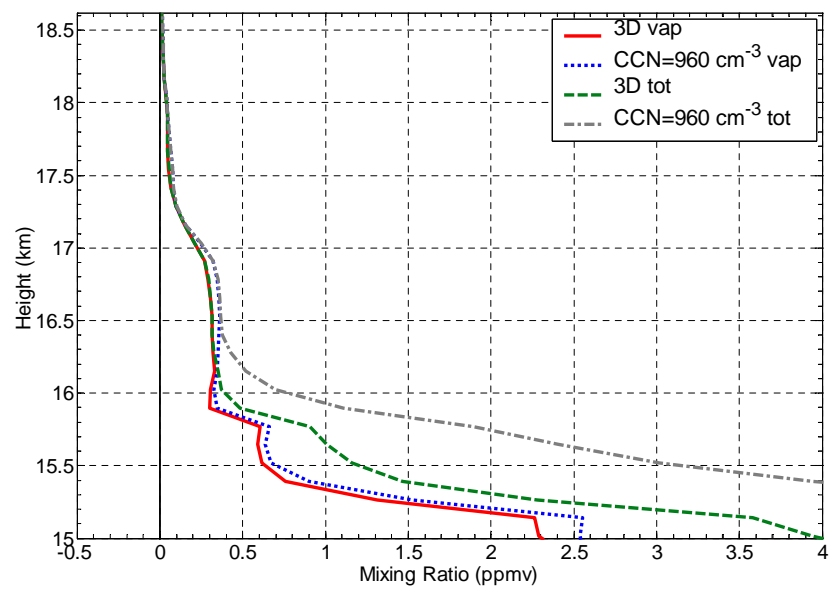

Fig. 17. As in Fig. 12, but for the 3D case and the high CCN case.
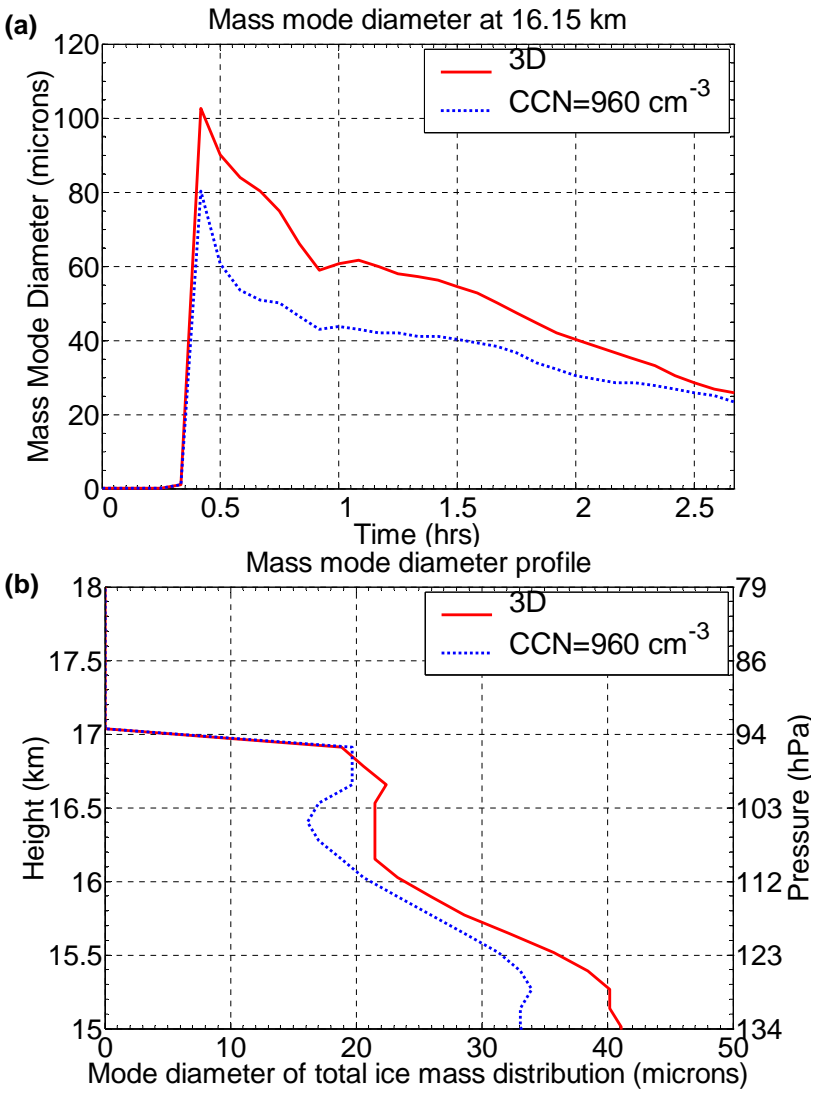

Fig. 18. (a) Time-series of the mode diameter of the mass mixing ratio size distribution of the total ice mass at $16.15 \mathrm{~km}$. The size distribution, as used for this calculation $\left(\mathrm{dq} \mathrm{dD}^{-1}, \mathrm{q}=\right.$ mixing ratio, $\mathrm{D}=$ diameter), is horizontally averaged across the domain. (b) Profile of this mode diameter at the end of the simulation. Both are shown for the "3-D" case and the high CCN 3-D case.

case) displays some of the maximum heights of the different reflectivity contours and shows that both the 35 and $40 \mathrm{dBZ}$ 


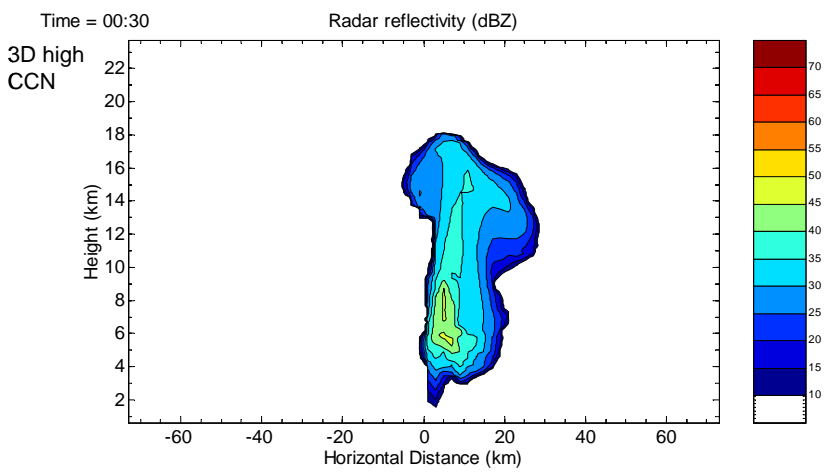

Fig. 19. Cross section of the simulated radar reflectivity of the 3-D hign $\mathrm{CCN}$ case taken though the slice inidicated in Fig. 6.

contours are considerably lower in the high $\mathrm{CCN}$ case. The differences are due to the fact that more of the water mass in the upper regions of the high $\mathrm{CCN}$ cloud is in the smallersized snow hydrometeor form rather than graupel, since the lack of warm rain produced in the lower regions of the cloud means that less graupel can form through raindrop freezing. Hence, the cloud has simulated reflectivities that are consistent with more of the observed clouds. When these higher frequencies are used in the calculation of $d Q$, combined with the higher amounts of moistening seen in the high CCN simulation, significantly higher values are obtained relative to the normal case (Table 3). For the $16-17 \mathrm{~km}$ height range, $d Q$ values of $\sim 0.1-0.3 \mathrm{ppmv}$ are predicted when using the different reflectivity contours and for the $15-16 \mathrm{~km}$ range, values of $0.3-1 \mathrm{ppmv}$ are produced.

In both cases, the calculations using the $35 \mathrm{dBZ}$ echo top statistics gave the smallest $d Q$ values since this contour still reached fairly high altitudes in the high $\mathrm{CCN}$ case. This suggests that an adjustment of the droplet number in the bulk microphysics scheme still cannot replicate the low reflectivities observed by the radar. In addition, it seems unlikely that droplet concentrations in the boundary layer were as high as those simulated in the high CCN case $\left(960 \mathrm{~cm}^{-3}\right)$ since the bulk of the region is likely to have been moderately unpolluted. Therefore, whilst suggesting that microphysical tuning may help to create clouds that better match the observations, it seems unlikely that the real clouds observed would have been affected by exactly the same microphysical pathways that led to reduced graupel formation in the high CCN simulation. Further investigation is required to look into the reasons for the discrepancies.

\subsection{Supporting observations from during HIBISCUS}

The idea of the injection of air into the stratosphere of this region by convection is supported by observations presented in Nielsen et al. (2007, hereafter referred to as N07) of solid particles in the lower stratosphere that were made a few days earlier and at the same location. Back trajectories showed

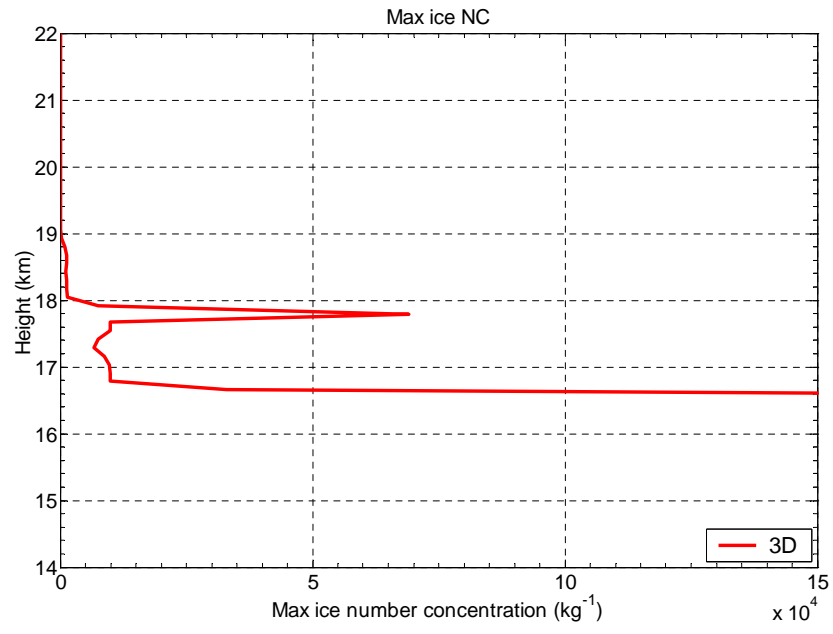

Fig. 20. Profile of the maximum ice number concentration at the end of the simulation for the " $3-\mathrm{D}$ " case.

the likelihood that these emanated from a particularly intense storm that reached $20 \pm 1 \mathrm{~km}$ in altitude and was located $\sim 200 \mathrm{~km}$ east of the observation location $\sim 5.5 \mathrm{~h}$ earlier. It was speculated that they may have been composed of ice or partly of NAT (nitric acid tri-hydrate), which would suggest that moistening had also occurred in order to prevent their evaporation.

Similar to the observations in N07, in the 3-D simulation of the most vigorous cloud (case "3-D"), an area with high ice number concentrations in a small region below $18 \mathrm{~km}$, above the main region of ice left over from the cloud, is present 3:35 h after the overshoot reached the TTL region as shown by the profile of maximum ice number concentration in Fig. 20. This result suggests that ice particles can survive at high altitudes for several hours after injection by deep convection, in concordance with the hypothesis presented in N07. It was suggested there that large water vapour concentrations of around $160 \mathrm{ppmv}$ were required to have been transported by the overshooting cloud, in order to allow the ice to survive for such a long period. Horizontal cross sections of the simulated vapour mixing ratio at $17.9 \mathrm{~km}$ (Fig. 21) show that moderately high vapour amounts of up to almost 9 ppmv were transported along with the ice particles in the simulation. This suggests that ice particles can survive in the presence of much lower vapour mixing ratios than the 160 ppmv suggested in N07.

The same plot shows that this region was subsaturated with respect to ice at this time by around $10 \%$ or more and hence sublimation of the ice would be expected to be occurring. However, the timeseries of the maximum supersaturation at this height (Fig. 22) shows that such subsaturation only occurred at this height during the last $50 \mathrm{~min}$ of the simulation. This early supersaturation was due to the cold temperatures produced by the cloud as it overshot its level of neutral buoyancy, with the air gradually warming and becoming subsaturated as it mixed with its surroundings. 

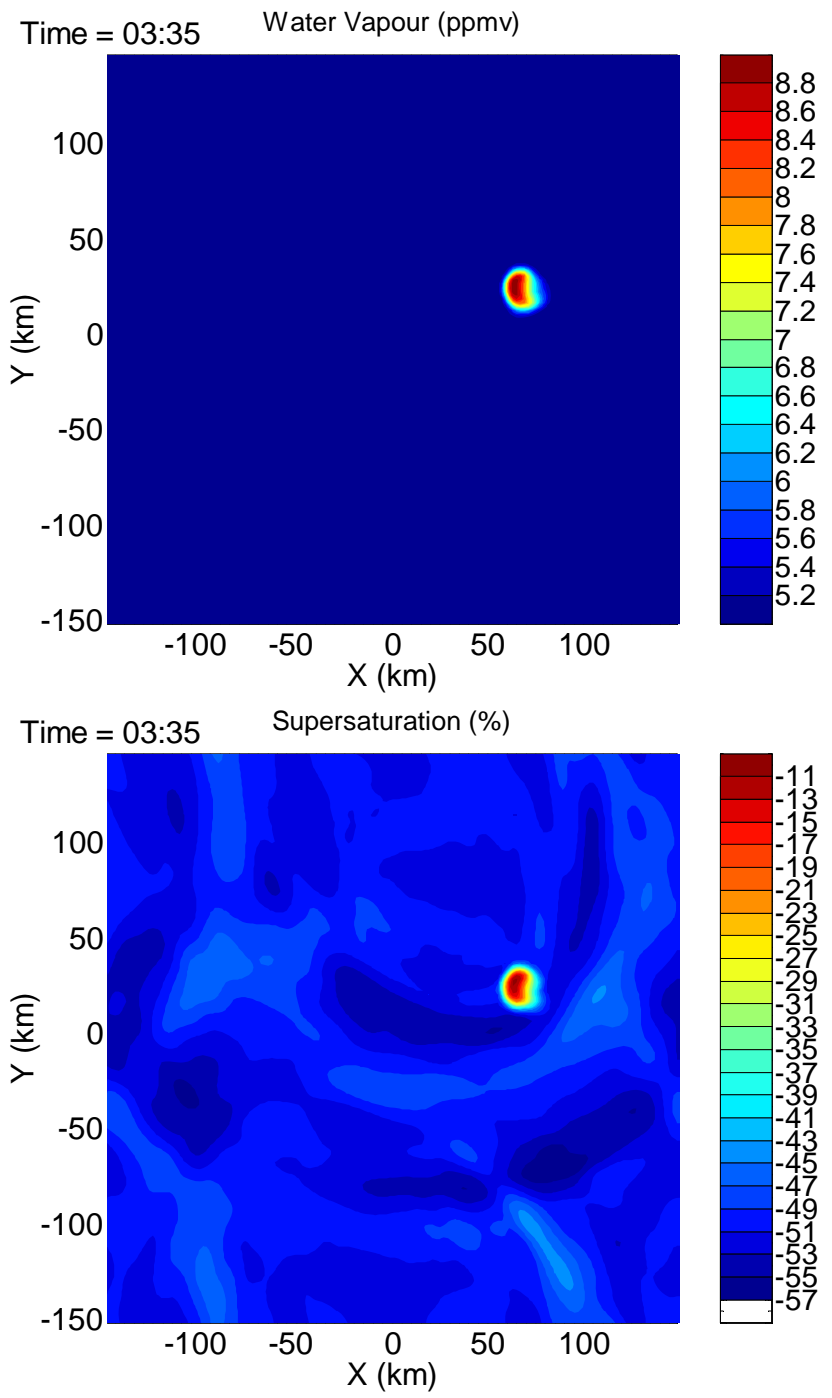

Fig. 21. Horizontal cross section of the water vapour mixing ratio (top) and the supersaturation with respect to ice (bottom) at the height of $17.9 \mathrm{~km}$ and at the end of the simulation for the " $3-\mathrm{D}$ " case. Note the minus signs on the colourbar of the plot on the right.

The region of the high ice number concentrations in the simulation was around $10 \mathrm{~km}$ in diameter, in agreement with the approximate horizontal dimension of the observed region of particles in N07. However, the number concentration at the end of the simulation is much lower than that inferred by the observations in $\mathrm{N} 07\left(0.4-10 \times 10^{6} \mathrm{~kg}^{-1}\right)$, believed to have been detected $\sim 5.5 \mathrm{~h}$ after injection by the storm. Such numbers were present earlier in the simulation at this height, though, with a peak simulated concentration of $1 \times 10^{7} \mathrm{~kg}^{-1}$.

Such regions of ice particles high in the stratosphere are not simulated in the weaker 3-D cases. The fact that only the simulation with the strongest convection matches the observations in this respect lends some support for the " 3 -D" case being representative of a significant number of the clouds oc-

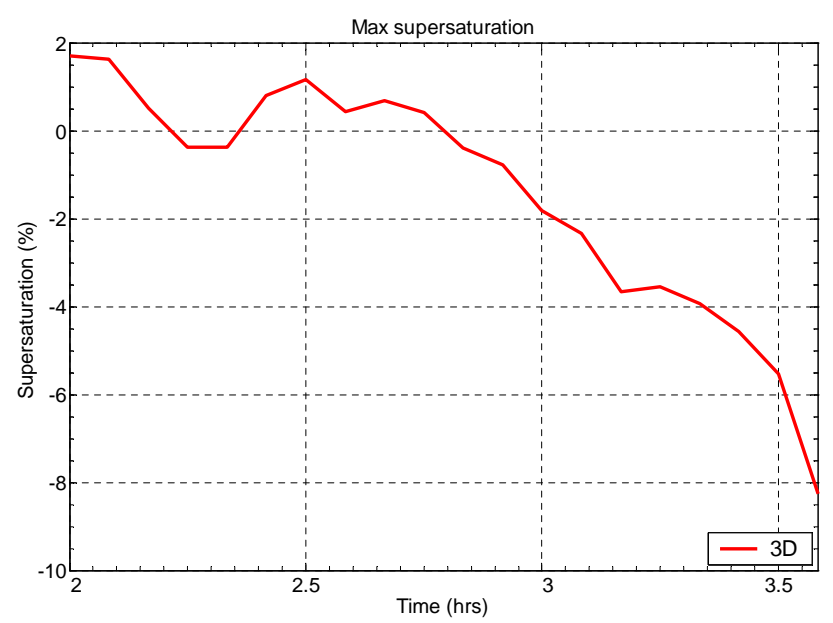

Fig. 22. Timeseries of the maximum supersaturation with respect to ice at $17.9 \mathrm{~km}$, towards the end of the simulation.

curring in nature, despite the lack of agreement with radar echo top heights for the higher reflectivity contours. If this is true, the larger moistening seen in this case may also be more representative of that occurring in reality. However, further investigation is required to determine the reason for the differences to the radar observations, before such conclusions can be drawn.

Further observational evidence for convective overshooting comes from profiles of $\mathrm{H}_{2} \mathrm{O}$ and $\mathrm{CH}_{4}$ made on the same day using the balloon-borne micro-SDLA instrument (Durry et al., 2006). These showed increases in water vapour from $\sim 16.5$ to just over $17 \mathrm{~km}$ that correlated with $\mathrm{CH}_{4}$ increases, suggesting an overshoot of convective air that caused a moistening in the TTL.

In addition, radiosonde measurements of temperature (Pommereau and Held, 2007) showed a cooling of the TTL and lower stratosphere, up to heights of $20 \mathrm{~km}$, that was larger at the times during the diurnal cycle when the highest echo top heights were observed ( 16:00 LT). Also, more cooling was observed during the periods of the campaign when the convection was the most active. These both suggest a significant effect of deep convection on the air at these heights and, hence, that significant convective moistening of the lower stratosphere may also be possible in this region.

\section{Conclusions}

CRM simulations performed in 2-D and 3-D showed conflicting effects of deep convection on the water content of air above the tropopause $(\sim 15.9 \mathrm{~km})$ with the 2 -D run predicting dehydration and the 3-D run moistening of a similar magnitude between 15.9 and $16.9 \mathrm{~km}$. The reason for the difference was that the 3-D simulation allowed more mixing between the ice-laden overshoot air and that of the TTL 
environment, resulting in increased ice sublimation. Sensitivity tests, performed using lower heating rates in order to generate less intense clouds, showed that even in clouds that reach lower heights than the 2-D cloud, moistening rather than dehydration was still produced. These results suggest that it is essential to use 3-D dynamics for such simulations in order to correctly predict the effect of overshoots on the TTL water content.

An estimate was made of the effect of such moistening on an air parcel passing through a region of convection, namely the South America region during the wet season, by using the average moistening predicted by the model over the height ranges of both $15-16 \mathrm{~km}$ and $16-17 \mathrm{~km}$. The time spent by a trajectory is approximated by the size of such a region, whilst assuming a constant wind speed of $5 \mathrm{~m} \mathrm{~s}^{-1}$. Based on the frequency of convection that was observed during the HIBISCUS/TROCCIBRAS campaign to have $10 \mathrm{dBZ}$ echo tops in line with those from the different simulated clouds, and assuming this convection to occur with the same frequency over the whole convective area, gives a fairly significant mean moistening of 0.26 and $0.13 \mathrm{ppmv}$ for the strongest and second strongest cases, respectively, between the heights of 16 and $17 \mathrm{~km}$. Since this is above the tropopause $(15.9 \mathrm{~km})$, this represents direct moistening of air that is very likely to remain stratospheric. The moistening in the weakest of the cases here was only 0.05 ppmv and hence is likely to be much less significant, unless the air parcel can experience many convective regions before it ascends beyond the influence of convection.

The air between 15 and $16 \mathrm{~km}$ is moistened by a much greater amount in the simulations and therefore the moistening predictions for the air parcel, based on $10 \mathrm{dBZ}$ radar statistics, are very significant, being $0.85,1.17$ and $2.8 \mathrm{ppmv}$ in the strong, medium and weak 3-D cases, respectively. More moistening is predicted for the weaker cases since they produced lower $10 \mathrm{dBZ}$ echo tops, which were consistent with more of the convective cells observed during the campaign. Since this air is below the tropopause, though, this requires that the air in these height ranges experiences future uplift across the tropopause via the Brewer Dobson circulation, in order to have a stratospheric effect. The height of net zero radiative uplift is currently thought to lie at $\sim 15 \pm 0.5 \mathrm{~km}$ (Gettelman et al., 2004), although this is subject to many other uncertainties, such as the potential for cloud itself to lower this height by $0.5-1 \mathrm{~km}$, as suggested by Corti et al. (2005).

Assessing the potential effect of convection on the stratospheric water vapour content is likely to be very dependent on the correct determination of this height since the radar statistics suggest that the instances of convection reaching these upper tropospheric regions are relatively common in the Bauru area. However, the stratospheric impact of any moistening will be limited by the ice saturation value at the coldest point during future ascent. Hence, the path that air trajectories take during the ascent will determine how much moistening of the stratosphere convection can provide, with the possibility that no effective stratospheric moistening is produced due to convection if sufficiently cold temperatures are reached.

In order to gauge the frequency that air parcels sample convective regions during ascent into the stratosphere and the coldest temperatures reached by them, a trajectory or global model approach is needed. These could model the different pathways of air as it travels horizontally, but with the inclusion of convective effects, as for example in Sherwood and Dessler (2001). This is beyond the scope of the current work here, but the work presented does suggest that overshooting convection is frequent enough and has enough of a moistening effect to potentially have an important global stratospheric effect.

One problem, highlighted by this work and other authors, with the use of a CRM with bulk microphysics for this type of work, is the tendency for the prediction of too high radar reflectivity values in the upper regions of the cloud. This means that if the tops of the 35 or $40 \mathrm{dBZ}$ echoes from the radar statistics are used for frequency predictions by comparing them to the heights achieved in the simulations, then very little moistening is suggested.

The majority of the reflectivity was identified as having come from graupel particles. Sensitivity tests using different graupel densities reveal little effect on the simulated radar reflectivity. Another possibility, yet to be explored, is that too many raindrops are freezing into graupel via heterogeneous nucleation, which may be the case if heterogeneous ice nuclei are less abundant than assumed by the parameterisations of this process.

It could be that the simulated updraughts are too high so as not to allow graupel to fall out, but since the reflectivity problem was still apparent in the "3-D-weak" case, which had a maximum $10 \mathrm{dBZ}$ echo top height that was considerably lower than many of the clouds observed, this seems unlikely. One further possibility is that the use of a convective initiation technique analogous to a warm bubble is the cause. Further investigation by comparison with more natural techniques would be desirable for future studies. One example would be to use a mesoscale model to simulate the synoptic environment in order to look at storm development through convergence and moisture transport from tropical regions, as occurs via the SACZ. The spinning up of the model wind and moisture fields to produce turbulent motions on a variety of scales and to allow mixing of moisture within the boundary layer may be an important process as described in Carpenter et al. (1998) since it might affect the entrainment of environmental air into the developing warm bubble. However, a finer horizontal resolution is required before this can be properly simulated and hence errors due to the latter are likely to overshadow any arising from issues involving spin up time. Use of satellite data, such as in Chaboureau et al. (2007) where observed brightness temperatures (BTs) were compared to those simulated, would facilitate comparisons of the smaller 
ice crystals. This would allow further probing of the discrepancies between the model and reality and might shed some light on the reasons for the differences in radar reflectivities as well as discerning whether these differences affect the processes at cloud top.

The results presented here suggest that microphysical considerations are likely to be very important to the way a cloud affects the TTL water content. The number concentration of ice in the simulated overshoot, as it reached the TTL region, was dominated by crystals that were transported from below the TTL, which formed mainly from the homogeneous freezing of liquid water droplets at $-38^{\circ} \mathrm{C}$. For this reason, in 3-D sensitivity tests, CCN increases were seen to enhance ice concentrations in the TTL region and led to increased ice evaporation above the tropopause, with $\sim 13 \%$ more vapour increase observed between 15 and $17 \mathrm{~km}$, relative to the increase in the normal case.

Very large increases in the amount of extra total water of 34 and $132 \%$ were found with increasing $\mathrm{CCN}$ for the $15-$ 16 and $16-17 \mathrm{~km}$ height ranges, respectively, indicating the presence of substantial additional ice. Whether this ice will sediment slowly enough to evaporate and cause a permanent moistening of the lower TTL is, however, uncertain, and will require further work over longer time scale simulations to ascertain. Having said this, the increases in vapour above the tropopause and the small sizes of the remaining ice suggest that aerosol increases near cloud base could potentially have an impact on the stratospheric vapour content, in agreement with Sherwood (2002). It may be possible that such variations could account for the observed increasing trend in stratospheric water vapour but further assessment of the global scale impact of deep convective water vapour effects are needed before the likelihood of this can be judged. An additional source of variability from aerosol effects may come through their potential impact on cloud dynamics. Some studies suggest that $\mathrm{CCN}$ numbers may affect the vigour of tropical, deep convection (e.g. Connolly et al., 2007). If this is the case, then the kind of variability in the moistening observed between the three different strengths of cases simulated here might be found in nature as a result of aerosol interactions, which would allow more potential stratospheric water vapour trend from aerosol effects.

These results are, of course, subject to the microphysical parameterisations employed by the model. Although a bulk microphysics scheme is used here, the prediction of increased droplet numbers at cloud base leading to increased ice numbers in the upper cloud is in agreement with explicit microphysics studies (e.g. Khain and Pokrovsky, 2004; Phillips et al., 2002). Improvements in the microphysical representation of aerosols are desirable for future studies, though. Sensitivity to the parameterisation of the fall speeds of ice should also be examined, given the lack of observational evidence and the importance of this to the residence time of ice in the TTL.
The current model does not include the effect of the homogeneous freezing of aerosol, only nucleation of heterogeneous ice nuclei. Jensen and Ackerman (2006) showed that the former process could be important in determining the ice number concentration in the upper regions of deep convection, in contrast to this work, where ice advected from below dominated the ice number in the TTL region. This could have implications for the effect of convection on the TTL water content since the homogeneous aerosol freezing in Jensen and Ackerman (2006) was shown to produce numerous small ice particles, which would be unlikely to sediment efficiently from the region and may prevent any dehydration effect or increase moistening. It might also reduce the sensitivity of the convective effect on TTL water content to aerosol loading in the boundary layer, since even clouds in a clean environment may still contain numerous haze droplets and hence produce relatively large ice number concentrations via homogeneous freezing of aerosol.

However, the onset of homogeneous freezing of aerosol is likely to require that most of the ice particles formed low in the cloud are removed by the time the cloud reaches high altitudes since the process requires high supersaturations of $\sim 60 \%$ and any remaining ice crystals will tend to act as a sink for vapour. It is unclear whether this would occur in all cases. In addition, any IN left over from nucleation further below, or entrained during ascent, may also prevent high supersaturations and therefore homogeneous aerosol freezing. Given the great uncertainty in IN concentrations and the representation of nucleation mechanisms, the effect of this is likely to be difficult to gauge using current microphysical models.

The simulated reflectivity in the high $\mathrm{CCN}$ case was found to be more realistic due to reduced graupel production through raindrop freezing, since less warm rain was produced by the smaller droplets. This suggests a possible microphysical cause for the discrepancies, but since the higher CCN number tested $\left(960 \mathrm{~cm}^{-3}\right)$ is likely to have been above that which occurred in the fairly unpolluted test region at the time of the HIBISCUS campaign, the exact microphysical mechanisms simulated in this sensitivity test seem unlikely to have occurred in reality.

It is unknown whether the microphysical differences suggested by the enhanced simulated reflectivities high in the cloud will have an effect on the amount of TTL moistening predicted by the model. Given that droplet number increases were found to have had an effect through ice fall speed considerations, this is a possibility. However, since graupel particles are relatively heavy, they are likely to quickly fall from the upper regions of the cloud and have little moistening effect. Therefore, the predicted vapour increases may be an underestimate compared to a situation where smaller ice particles were formed, although it is possible be that more complicated microphysical feedbacks, due to the extra graupel, have a compensating effect. The fact that the convection in the studied season was observed to have been less intense 
than other documented seasons also points towards a possible underestimation of the convective moistening effect.

Whether or not deep convection can significantly affect the stratospheric vapour content depends on how often such TTL penetrating events occur; their spatial distribution; whether the clouds cause dehydration or moistening and the magnitude of such effects; and how much air is actually detrained by them. Thus, the observational and modelling challenges span from a global scale down to the study of individual clouds. The simulations presented here represent only a handful of clouds out of the range occurring naturally. Further modelling studies of clouds of various strengths and in a variety of different environmental conditions, as well investigations into microphysical aspects, particularly the issue of the simulated reflectivities being too high, are needed before CRMs with bulk microphysics, such as the one used here, can be reliably deployed to predict convective effects on the TTL water content.

\section{Appendix A}

\section{The calculation of the siumlated radar reflectivities}

The simulated radar reflectivities are calculated for the model hydrometeor fields of rain, cloud ice, snow and graupel using the following (see e.g., Hogan et al., 2006, for more details):

$$
\begin{aligned}
& Z\left[\mathrm{~mm}^{6} \mathrm{~m}^{-3}\right]=10^{18} \frac{\left|K_{x}\right|^{2}}{0.93}\left(\frac{6}{\pi \rho_{i}}\right)^{2} \\
& \int_{0}^{\infty} n_{x}(D) m_{x}(D)^{2} d D \\
& Z_{\mathrm{dBZ}}[\mathrm{dBZ}]=10 \log _{10}(Z)
\end{aligned}
$$

$x$ denotes the hydrometeor type; $|K x|^{2}$ is the dielectric factor for which a value of 0.174 is used for the ice hydrometeors (ice, snow and graupel) and a value of 1 for the rain hydrometeor; $\rho_{i}$ is the density of solid ice; $n_{x}(D) d D$ is the number density of hydrometeor $x$ over the size range $d D$; and $m_{x}(D)$ is the mass of a hydrometeor of type $x$ with diameter $D$. The hydrometeor mass is calculated according to:

$m_{x}(D)=c_{x} D^{d_{x}}$

The constants $c_{x}$ and $d_{x}$ are given in Table A1 for each hydrometeor. The number distribution as a function of size is assumed to be a gamma distribution with different parameters for each hydrometeor:

$n_{x}(D)=n_{x 0} D^{\alpha_{x}} e^{-\lambda_{x} D}$

Here $\alpha_{x}$ is a constant given in Table A1. $\lambda_{x}$ is calculated from the mass mixing ratio field and the above equations for the single moment rain hydrometeor, whereas the calculation also uses the number concentration for the double moment ice, snow and graupel hydrometeors. For the single moment
Table A1. Constants used for the different hydrometeors in the LEM microphysics scheme.

\begin{tabular}{llll}
\hline Hydrometeor & & & \\
$x$ & $c_{x}$ & $d_{x}$ & $\alpha_{x}$ \\
\hline Rain & 523.6 & 3 & 2.5 \\
Ice & 104.0 & 3 & 0 \\
Snow & 52.36 & 3 & 2.5 \\
Graupel & 261.8 & 3 & 2.5 \\
\hline
\end{tabular}

rain hydrometeor $n_{x 0}$ is assumed to have a constant value of $1.1 \times 10^{15}$ whereas for the double moment hydrometeors $n_{x 0}$ can be calculated from the number concentration field and $\lambda_{x}$.

Acknowledgements. The authors thank the coordinators of TroCCiBras and the personnel of the Meteorological Research Institute (IPMet) of the São Paulo State University (UNESP) for providing the infrastructure to host HIBISCUS, as well as H. A. G. França for assisting with the retrieval and pre-processing of the raw radar data. NCAR is acknowledged for making available the latest version of TITAN. More thanks go to the HIBISCUS organisers J.-P. Pommereau and A. Garnier and to all the participants.

Edited by: R. MacKenzie

\section{References}

Black, T. L.: The New Nmc Mesoscale Eta-Model - Description and Forecast Examples, Weather and Forecasting, 9, 265-278, 1994.

Brewer, A. W.: Evidence for a World Circulation Provided by the Measurements of Helium and Water Vapour Distribution in the Stratosphere, Q. J. Roy. Meteor. Soc., 75, 351-363, 1949.

Brown, A. R., Derbyshire, S. H., and Mason, P. J.: Large-eddy simulation of stable atmospheric boundary layers with a revised stochastic subgrid model, Q. J. Roy. Meteor. Soc., 120, 14851512, 1994.

Carpenter Jr., R. L., Droegemeier, K. K., and Blyth, A. M.: Entrainment and detrainment in numerically simulated cumulus congestus clouds. Part I: General results., J. Atmos. Sci., 55, 34173432, 1998.

Chaboureau, J.-P., Cammas, J.-P., Duron, J., Mascart, P. J., Sitnikov, N. M., and Voessing, H.-J.: A numerical study of tropical crosstropopause transport by convective overshoots, Atmos. Chem. Phys., 7, 1731-1740, 2007, http://www.atmos-chem-phys.net/7/1731/2007/.

Connolly, P., Choularton, T., Gallagher, M., Bower, K., Flynn, M., and Whiteway, J.: Cloud resolving simulations of intense tropical, Hector thunderstorms: Implications for aerosolcloud interactions, Q. J. Roy. Meteor. Soc., 132, 3079-3106, doi:10.1256/qj.05.86, 2006.

Corti, T., Luo, B. P., Peter, T., Vomel, H., and Fu, Q.: Mean radiative energy balance and vertical mass fluxes in the equatorial 
upper troposphere and lower stratosphere, Geophys. Res. Lett., 32, L06802, doi:10.1029/2004GL021889, 2005.

Danielsen, E. F.: A Dehydration Mechanism for the Stratosphere, Geophys. Res. Lett., 9, 605-608, 1982.

Dessler, A. E., Palm, S. P., and Spinhirne, J. D.: Tropical cloud-top height distributions revealed by the Ice, Cloud, and Land Elevation Satellite (ICESat)/Geoscience Laser Altimeter System (GLAS), J. Geophys. Res.-Atmos., 111, D12215, doi:10.1029/2005JD006705, 2006.

Dixon, M. and Wiener, G.: Titan - Thunderstorm Identification, Tracking, Analysis, and Nowcasting - a Radar-Based Methodology, J. Atmos. Oceanic Technol., 10, 785-797, 1993.

Durry, G., Huret, N., Hauchecorne, A., Marecal, V., Pommereau, J.-P., et al.: Isentropic advection and convective lifting of water vapour in the UT - LS as observed over Brazil $\left(22^{\circ} \mathrm{S}\right)$ in February 2004 by in situ high-resolution measurements of $\mathrm{H}_{2} 0, \mathrm{CH}_{4}$, $\mathrm{O}_{3}$ and temperature., Atmos. Chem. Phys. Discuss., 6, 12469 12 501, 2006.

Ferrier, B. S.: A Double-Moment Multiple-Phase 4-Class Bulk Ice Scheme.1. Description, J. Atmos. Sci., 51, 249-280, 1994.

Ferrier, B. S., Tao, W. K., and Simpson, J.: A Double-Moment Multiple-Phase 4-Class Bulk Ice Scheme. 2. Simulations of Convective Storms in Different Large-Scale Environments and Comparisons with Other Bulk Parameterizations, J. Atmos. Sci., 52, 1001-1033, 1995.

Flatau, P. J.: The CSU-RAMS cloud microphysics module general theory and code documentation., Colorado State University, Paper No. 451., 88pp., 1989.

Fueglistaler, S., Bonazzola, M., Haynes, P. H., and Peter, T.: Stratospheric water vapor predicted from the Lagrangian temperature history of air entering the stratosphere in the tropics, J. Geophys. Res.-Atmos., 110, D08107, doi:10.1029/2004JD005516, 2005.

Fueglistaler, S. and Haynes, P. H.: Control of interannual and longer-term variability of stratospheric water vapor, J. Geophy. Res.-Atmos., 110, D24108, doi:10.1029/2005JD006019, 2005.

Fueglistaler, S., Wernli, H., and Peter, T.: Tropical troposphere-to-stratosphere transport inferred from trajectory calculations, J. Geophy. Res.-Atmos., 109, D03108, doi:10.1029/2003JD004069, 2004.

Gettelman, A., Forster, P. M. D., Fujiwara, M., Fu, Q., Vomel, H., et al.: Radiation balance of the tropical tropopause layer, J. Geophys. Res.-Atmos., 109(D7), D07103, doi:10.1029/2003JD004190, 2004.

Gomes, A. M. and Held, G.: Determinação e avaliação do parâmetro densidade VIL para alerta de tempestades., Proceedings, XIII Congresso Brasileiro de Meteorologia, (CDROM), Fortaleza, 29 August-3 September 2004, SBMET, 12, 2004.

Gupta, A.: Geoindicators for tropical urbanization, Environ. Geol., 42, 736-742, 2002.

Held, G., Calheiros, R. V., and Gomes, A. M.: O Projeto TroCCiBras: Objetivos, resultados da campanha 2004 e o futuro., Proceedings, XIV Congresso Brasileiro de Meteorologia, (CD ROM), Florianópolis, 27 November-1 December 2006, SBMET., 6, 2006.

Hogan, R. J., Mittermaier, M. P., and Illingworth, A. J.: The retrieval of ice water content from radar reflectivity factor and temperature and its use in evaluating a mesoscale model, J. Appl. Meteorol. Climatol., 45, 301-317, 2006.

Holton, J. R. and Gettelman, A.: Horizontal transport and the dehy- dration of the stratosphere, Geophys. Res. Lett., 28, 2799-2802, 2001.

Holton, J. R., Haynes, P. H., Mcintyre, M. E., Douglass, A. R., Rood, R. B., and Pfister, L.: Stratosphere-Troposphere Exchange, Rev. Geophys., 33, 403-439, 1995.

Jensen, E. J. and Ackerman, A. S.: Homogeneous aerosol freezing in the tops of high-altitude tropical cumulonimbus clouds, Geophys. Res. Lett., 33, L08802, doi:10.1029/2005GL024928, 2006.

Kessler, E.: On the distribution and continuity of water substance in atmospheric circulation, Meteoro. Monogr., 10, 84pp., 1969.

Khain, A. and Pokrovsky, A.: Simulation of effects of atmospheric aerosols on deep turbulent convective clouds using a spectral microphysics mixed-phase cumulus cloud model. Part II: Sensitivity study, J. Atmos. Sci., 61, 2983-3001, 2004.

Kousky, E. M.: Pentad outgoing longwave radiation climatology for the South American sector., Revista Brasileira de Meteorologia, 3, 217-231, 1988.

Kuang, Z. M. and Bretherton, C. S.: Convective influence on the heat balance of the tropical tropopause layer: A cloud-resolving model study, J. Atmos. Sci., 61, 2919-2927, 2004.

Küpper, C., Thuburn, J., Craig, G. C., and Birner, T.: Mass and water transport into the tropical stratosphere: A cloudresolving simulation, J. Geophy. Res.-Atmos., 109, D10111, doi:10.1029/2004JD004541, 2004.

Lane, T. P. and Knievel, J. C.: Some effects of model resolution on simulated gravity waves generated by deep, mesoscale convection, J. Atmos. Sci., 62, 3408-3419, 2005.

Lane, T. P., Sharman, R. D., Clark, T. L., and Hsu, H. M.: An investigation of turbulence generation mechanisms above deep convection, J. Atmosp. Sci., 60, 1297-1321, 2003.

Lin, Y. L., Farley, R. D., and Orville, H. D.: Bulk Parameterization of the Snow Field in a Cloud Model, J. Climate Appl. Meteorol., 22, 1065-1092, 1983.

Liu, C. T. and Zipser, E. J.: Global distribution of convection penetrating the tropical tropopause, J. Geophys. Res.-Atmos., 110, D23104, doi:10.1029/2005JD006063, 2005.

Meyers, M. P., DeMott, P. J., and Cotton, W. R.: New primary icenucleation parameterizations in an explicit cloud model., J. Appl. Meteor., 31, 708-721, 1992.

Naccarato, K. P., Pinto Jr., O., and Held, G.: Climatology of Lightning in Brazil - Overview and Comparison to the Campaign Period, Proceedings, HIBISCUS/TroCCiBras/TROCINOX Workshop, Bauru, SP, 16-19 November 2004, p10. http://www.ipmet. unesp.br/troccibras, 2004.

Newell, R. E. and Gould-Stewart, S.: A Stratospheric Fountain, J. Atmos. Sci., 38, 2789-2796, 1981.

Nielsen, J. K., Larsen, N., Cairo, F., and Di Donfrancesco, G.: Solid particles in the tropical lowest stratosphere, Atmos. Chem. Phys., 7, 685-695, 2007, http://www.atmos-chem-phys.net/7/685/2007/.

Oltmans, S. J. and Hofmann, D. J.: Increase in Lower-Stratospheric Water-Vapor at a Mid-Latitude Northern-Hemisphere Site from 1981 to 1994, Nature, 374, 146-149, 1995.

Petch, J. C., Brown, A. R., and Gray, M. E. B.: The impact of horizontal resolution on the simulations of convective development over land, Q. J. Roy. Meteor. Soc., 128, 2031-2044, 2002.

Phillips, V. T. J., Choularton, T. W., Blyth, A. M., and Latham, J.: The influence of aerosol concentrations on the glaciation and precipitation of a cumulus cloud, Q. J. Roy. Meteor. Soc., 128, 
951-971, 2002.

Pommereau, J.-P. and Held, G.: Is there a stratospheric fountain? Atmos. Chem. Phys. Discuss., 7, 8933-8950, 2007, http://www.atmos-chem-phys-discuss.net/7/8933/2007/.

Pommereau, J.-P., Letrenne, G., F., V., Hertzog, A., Legras, B., et al.: An overview of the HIBISCUS campaign, Atmos. Chem. Phys. Disucss., 7, 2389-2475, 2007.

Redelsperger, J. L., Brown, P. R., Guichard, F., Hoff, C., Kawasima, M., et al.: A GCSS model intercomparison for a tropical squall line observed during TOGA-COARE. I: Cloud-resolving models, Q. J. Roy. Meteor. Soc., 126, 823-864, 2000.

Robinson, F. J. and Sherwood, S. C.: Modeling the impact of convective entrainment on the tropical tropopause, J. Atmos. Sci., 63, 1013-1027, 2006.

Rosenfeld, D. and Woodley, W. L.: Deep convective clouds with sustained supercooled liquid water down to -37.5 degrees $\mathrm{C}$, Nature, 405, 440-442, 2000.

Rosenlof, K. H., Oltmans, S. J., Kley, D., Russell, J. M., Chiou, E. W., et al.: Stratospheric water vapor increases over the past half-century, Geophys. Res. Lett., 28, 1195-1198, 2001.

Rutledge, S. A. and Hobbs, P. V.: The Mesoscale and Microscale Structure and Organization of Clouds and Precipitation in Midlatitude Cyclones.12. A Diagnostic Modeling Study of Precipitation Development in Narrow Cold-Frontal Rainbands, J. Atmos. Sci., 41, 2949-2972, 1984.

Seidel, D. J., Ross, R. J., Angell, J. K., and Reid, G. C.: Climatological characteristics of the tropical tropopause as revealed by radiosondes, J. Geophys. Res.-Atmos., 106, 7857-7878, 2001.

Sherwood, S.: A microphysical connection among biomass burning, cumulus clouds, and stratospheric moisture, Science, 295, 1272-1275, 2002.
Sherwood, S. C. and Dessler, A. E.: On the control of stratospheric humidity, Geophys. Res. Lett., 27, 2513-2516, 2000.

Sherwood, S. C. and Dessler, A. E.: A model for transport across the tropical tropopause, J. Atmos. Sci., 58, 765-779, 2001.

Shutts, G. J. and Gray, M. E. B.: A numerical modelling study of the geostrophic adjustment process following deep convection., Quart. J. R. Meteorol. Soc., 120, 1145-1178, 1994.

Simpson, J., Keenan, T. D., Ferrier, B., Simpson, R. H., and Holland, G. J.: Cumulus Mergers in the Maritime Continent Region, Meteorol. Atmos. Phys., 51, 73-99, 1993.

Swann, H.: The development and validation of a microphysics scheme for cloud resolving model simulations of deep convection, PhD thesis, University of Reading, 1996.

Swann, H.: Sensitivity to the representation of precipitating ice in CRM simulations of deep convection., Atmos. Res., 48, 415435, 1998.

Twomey, S.: The nuclei of natural cloud formation. Part II: the supersaturation in natural clouds and the variation of cloud droplet concentration., Geophys. Pura. Appl., 43, 243-249., 1959.

Wang, P. K.: Moisture plumes above thunderstorm anvils and their contributions to cross-tropopause transport of water vapor in midlatitudes, J. Geophys. Res.-Atmos., 108(D6), 4194, doi:10.1029/2003JD002581, 2003.

Wu, D. L., Read, W. G., Dessler, A. E., Sherwood, S. C., and Jiang, J. H.: UARS/MLS cloud ice measurements: Implications for H2O transport near the tropopause, J. Atmos. Sci., 62, 518-530, 2005.

Zhou, X. L., Geller, M. A., and Zhang, M. H.: Cooling trend of the tropical cold point tropopause temperatures and its implications, J. Geophys. Res.-Atmos., 106, 1511-1522, 2001. 